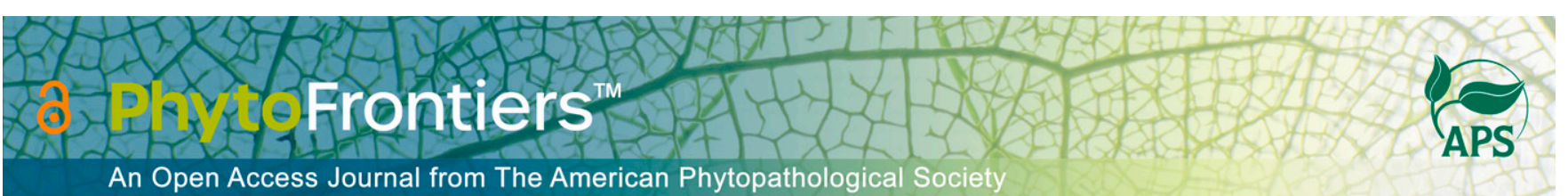

\title{
Research
}

\section{Distinct Arabidopsis Responses to Two Generalist Caterpillar Species Differing in Host Breadth}

\author{
Zhihong Zhang $^{1} \mid$ Andreas Schedl $^{2,3} \mid$ Rebekka Sontowski ${ }^{2,3} \mid$ Brian T. Driscoll $^{4} \mid$ Nicole M. van Dam ${ }^{2,3} \mid$ \\ Jacqueline C. Bede ${ }^{1,4,+}$ (D) |
}

${ }^{1}$ Department of Plant Science, McGill University, Ste-Anne-de-Bellevue, Quebec, H9X 3V9, Canada

2 German Centre for Integrative Biodiversity Research (iDiv) Halle-Jena-Leipzig, D-04103 Leipzig, Germany

${ }^{3}$ Institute of Biodiversity, Friedrich Schiller University Jena, 07743 Jena, Germany

${ }^{4}$ Department of Natural Resource Sciences, McGill University, Ste-Anne-de-Bellevue, Quebec, H9X $3 \mathrm{~V} 9$, Canada

${ }^{\dagger}$ Corresponding author: J. Bede; jacqueline.bede@mcgill.ca

Accepted for publication 7 August 2020.

\section{Funding}

The authors thank their funding sources for supporting this research: the German Research Foundation (FZT 118) (RS, AS, NMvD) and the Natural Science and Engineering Research Council (NSERC) Discovery grant (NSERC 2019-04516) (JCB).

The author(s) declare no conflict of interest.

$\boldsymbol{e}$-Xtra: Supplementary materials are available online.

\begin{abstract}
In general, caterpillar herbivores with a narrow host preference (specialists) have evolved mechanisms to circumvent specific plant defenses. In contrast, caterpillars with a broader host range (generalists) may manipulate phytohormone pathways common to many plant species to attenuate induced defenses. Many studies have compared plant responses to specialist versus generalist caterpillars. In contrast, this study evaluates the induced response of Arabidopsis thaliana to two generalist caterpillar species, the cabbage looper, Trichoplusia ni, and the beet armyworm, Spodoptera exigua. Although both caterpillars are considered generalists, $S$. exigua has a broader plant host range, whereas $T$. ni prefers Brassicaceous plants. Our study shows that most responses to caterpillar herbivory, such as the jasmonate burst, are similar in plants attacked by either insect species; however, we do observe dynamic and temporal differences in specific responses. Expression of AtZAT10, a 12-oxo-phytodienoic acid-responsive gene, is only induced in response to $T$. $n i$ damage. In comparison, only $S$. exigua herbivory activates the salicylic acid/NPR1-dependent pathway, as observed by the expression of the marker gene AtPR1. Even though both species induce AtPDF1.2 expression, we found caterpillar-specific temporal differences: $T$. $n i$ herbivory results in sustained expression over time, whereas gene expression is sharply downregulated at $36 \mathrm{~h}$ in S. exigua-attacked plants. Although damage by these two caterpillar species induced AtMYB28 and AtMYB34 expression, specific shortand long-chain aliphatic and indolic glucosinolates accumulate only in response to $S$. exigua herbivory. These species-specific, plant-induced responses likely reflect differences in effectors found in caterpillar oral secretions.
\end{abstract}

Keywords: caterpillar, glucosinolates, phytohormone crosstalk, Spodoptera exigua, Trichoplusia ni 
Plants are remarkably sophisticated at differentiating between different biotic attackers to appropriately target their defense responses (Erb and Reymond 2019; Schuman and Baldwin 2016). When a plant leaf is damaged, either mechanically or by caterpillar herbivores, damage-associated molecular patterns (DAMPs) lead to a robust increase in jasmonate-related phytohormones (12-oxo-phytodienoic acid [OPDA], jasmonic acid [JA], (+)-7-iso-jasmonyl-L-isoleucine [JA-Ile]) (Acevedo et al. 2015; Erb and Reymond 2019; Wasternack and Hause 2013). This jasmonate burst leads to generalized downstream responses, which are modified by multiple inputs that are specific to the attacker (Acevedo et al. 2015; Basu et al. 2018; Danner et al. 2018). These inputs include footprints, feeding style, and effectors secreted through oral secretions (e.g., ventral eversible gland, regurgitant, and labial and mandibular saliva) that are known as herbivore-associated molecular patterns (HAMPs). Based on the HAMPs perceived by the plant, specific combinations of phytohormones are triggered. Three main pathways that modify jasmonate-responsive signaling are mediated by the phytohormones ethylene, abscisic acid (ABA), or salicylic acid (SA) (Robert-Seilaniantz et al. 2011). The interactions between these phytohormone-mediated pathways through dynamic, complex crosstalk at multiple signaling nodes lead to downstream responses that are reflected in specific plant responses to distinct herbivores (Ballaré 2011; Caarls et al. 2015; Howe et al. 2018).

In Arabidopsis thaliana (hereafter referred to as arabidopsis), foliar damage incurred by wounding or caterpillar herbivory leads to changes that initiate the biosynthesis of oxylipin jasmonates from 18C galactolipids in the chloroplast membrane (Erb and Reymond 2019; Howe et al. 2018; Wasternack and Hause 2013). Two jasmonate compounds, OPDA and JA-Ile, are recognized to initiate signaling pathways leading to distinct transcriptional responses (Taki et al. 2005; Wasternack and Song 2017; Zander et al. 2020). Of these two, far more is understood about the role of JA-Ile in regulating gene expression (Howe et al. 2018; Wasternack and Hause 2013). JA-Ile acts as a bridge, stabilized by inositol pentakisphosphate, bringing together the $\mathrm{SCF}^{\mathrm{COI} 1}$ complex to negative regulator jasmonate-ZIM domain (JAZ) proteins (Chini et al. 2007; Sheard et al. 2010; Yan et al. 2009). Upon recognition of the complex, CUL-RING E3 ligase binds and catalyzes the ubiquitation of the JAZ proteins, targeting them for degradation by the 26S-proteasome, thereby releasing MYC 2/3/4 transcription factors from the JAZ-NINJA-TOPLESS regulation complex and allowing jasmonate-responsive, COI1-dependent transcript expression (Pauwels et al. 2010; Thines et al. 2007).

Other phytohormone signaling pathways modify these jasmonate-dependent responses (see the last figure in this article for the proposed model) (Ballaré 2011; Caarls et al. 2015; Howe et al. 2018). In arabidopsis, the ethylene pathway acts synergistically to positively induce expression of JA-responsive marker genes such as AtHEL/PR4 and AtPDF1.2 via the transcription factor ORA59 (Pré et al. 2008). However, other transcription factors also effect the expression of these genes, leading to dynamic temporal responses. For example, the jasmonateresponsive MYC2 negatively regulates the expression of jasmonate/ethylene-responsive AtHEL/PR4 and AtPDF1.2 genes (Abe et al. 2003; Anderson et al. 2004; Dombrecht et al. 2007): Therefore, in response to methyl jasmonate treatment, the late expression of AtPDF1.2 may reflect an early transient increase in AtMYC2 levels that temporarily represses this gene (Anderson et al. 2004). Thus, it is of interest to evaluate gene expression dynamics temporally after caterpillar herbivory.

ABA often acts synergistically with jasmonates to activate AtMYC-responsive gene expression and, thus, antagonistically to jasmonate/ethylene-responsive gene expression (Abe et al. 2003; Anderson et al. 2004; Dombrecht et al. 2007; Nakata et al.
2013). Thus, ABA enhances jasmonate-mediated AtVSP2 expression but antagonizes the ethylene ORA59 branch that leads to AtPDF1.2 expression (Anderson et al. 2004; Bodenhausen and Reymond 2007; Lorenzo et al. 2004; Pangesti et al. 2016; Proietti et al. 2018; Vos et al. 2013).

SA and jasmonate/ethylene pathways often play antagonistic roles to optimize plant responses to the environment and interacting organisms, particularly pests and pathogens (Beckers and Spoel 2006: Caarls et al. 2015; Li et al. 2019). Activation of the SA pathway leads to changes in cellular redox balance that activates thioredoxins to reduce intermolecular disulfide bridges between NPR1 oligomers, releasing the monomeric form (Koornneef et al. 2008; Mou et al. 2003; Tada et al. 2008). Upon entry to the nucleus, NPR1 recruits TGA2, TGA5, and TGA6 transcription factors that bind to promoter regions (G-box elements) to suppress JA-dependent gene expression and induce expression of SA/NPR1-dependent marker genes, such as AtPR1 (Després et al. 2003; Lindermayr et al. 2010; Ndamukong et al. 2007; Spoel et al. 2003). It is of interest that the NPR1-dependent pathway suppresses expression of the JA/ethylene marker gene AtPDF 1.2, even though transcript expression of this gene by JA is also TGA 2/5/6 dependent (Ndamukong et al. 2007; Spoel et al. 2003; Zander et al. 2010). The SA-associated pathway can also interfere with jasmonate/ethylene-responsive gene expression through an NPR1-independent pathway (Leon-Reyes et al. 2009; Shearer et al. 2012). Similar to ABA, SA also inhibits the ethylene ORA59 pathway through suppression of transcript expression (Anderson et al. 2004; Lorenzo et al. 2004; Van der Does et al. 2013; Zander et al. 2014). In this pathway, the SAdependent, NPR1-independent GRXC9 binds to and represses TGA and AP2/ERF transcription factors to suppress AtORA59 gene expression (Herrera-Vásquez et al. 2015). Activation of the SA pathway also promotes EIN3-mediated degradation of ORA59 by the $26 S$-proteasome (He et al. 2017). Thus, ORA59 represents an important signaling node between phytohormone networks as levels are impacted positively or negatively by jasmonates or SA, respectively. However, it is noteworthy that high cellular ethylene levels reduce the effectiveness of the SAmediated suppression of jasmonate/ethylene-responsive gene expression (Leon-Reyes et al. 2010a, 2010b). Although SA and ABA both suppress jasmonate-responsive AtPDF1.2 expression, it is thought that this occurs via distinct mechanisms (Anderson et al. 2004; Caarls et al. 2015).

One group of specialized metabolites present in leaf tissue of plants in the Brassicales are nitrogen- and sulfur-rich glucosinolates (GSLs) that are important defensive compounds against caterpillar pests (Beekwilder et al. 2008; Halkier and Gershenzon 2006; Hopkins et al. 2009; Howe and Jander 2008; Li et al. 2000; Mewis et al. 2005, 2006; Müller et al. 2010; Pangesti et al. 2016; Schlaeppi et al. 2008). Depending on their biosynthetic route, GSLs are divided into aliphatic (primarily methionine-derived), aromatic (phenylalanine- or tyrosine-derived), or indolic (tryptophan-derived), with aliphatic and indolic GSLs being present in arabidopsis foliage (Brown et al. 2003; Hanschen et al. 2018; Kliebenstein et al. 2001). As plant specialized metabolites, they are relatively unique because they have a $\beta$-D-thioglucoside linked to their sulfonated aldoxime core (Halkier and Gershenzon 2006). In arabidopsis leaves, GSLs are stored in vacuoles of $S$ cells that are located along the midrib and leaf margins (Burow and Halkier 2017; Hunziker et al. 2019; Koroleva and Cramer 2011; Koroleva et al. 2010). When the leaf is damaged by chewing insect herbivores, this releases endoplasmic reticulum body-associated myrosinases ( $\beta$-thioglucoside hydrolases) from neighboring myrosin cells to cleave the thioglucoside linkage and release the highly unstable compounds that form isothiocyanates 
and nitriles, which are toxic to many insect herbivores (Hanschen et al. 2018; Wittstock and Burow 2010).

In arabidopsis rosettes, GSLs are present constitutively, but levels increase in response to wounding or insect herbivory (Wittstock and Gershenzon 2002), reflecting the induction of biosynthetic genes by AtMYB transcription factors and/or transport from undamaged tissues (Andersen et al. 2013; Burow and Halkier 2017; Madsen et al. 2014; Nintemann et al. 2018). Transcription factors AtMYB28, AtMYB29, and AtMYB76 are responsible for the induction of genes involved in aliphatic GSL biosynthesis (Gigolashvili et al. 2007a, 2008); specifically, AtMYB28 and AtMYB29 are involved in short-chain GSL biosynthesis with AtMYB76 requiring their presence ( $\mathrm{Li}$ et al. 2013). AtMYB29 is also involved in the regulation of long-chain GSLs biosynthesis (Gigolashvili et al. 2008; Li et al. 2018). Transcription factors AtMYB34, AtMYB51, and AtMYB122 regulate the expression of genes involved in indolic GSL biosynthesis (Gigolashvili et al. 2007b).

Jasmonate treatment induces AtMYB34, AtMYB51 and AtMYB122, as well as $A t M Y B 29$, gene expression (Dombrecht et al. 2007; Guo et al. 2013; Hirai et al. 2007; Mikkelsen et al. 2003). The resultant increase in foliar aliphatic and indolic GSL levels may be enhanced by ABA treatment (Guo et al. 2013; Nintemann et al. 2018). In contrast, SA treatment results in lower AtMYB28 levels (Gigolashvili et al. 2008). Treatment of arabidopsis with low SA levels increases GSL levels, both aliphatic and indolic, whereas treatment with $50 \mu \mathrm{M}$ SA decreases foliar GSL levels (Guo et al. 2013). Moreover, GSLs are bidirectionally transported or translocated between shoot and root tissues (Andersen et al. 2013; Touw et al. 2020). Grafting experiments show that, in particular, shortchain aliphatic GSLs are synthesized and stored in the vegetative rosette, whereas long-chain aliphatic and indolic GSLs are synthesized and possibly transported between shoots and roots.

Caterpillar species have different mechanisms to cope with GSLs and their breakdown products (Jeschke et al. 2016). Thus, the effect of GSL type, aliphatic or indolic, on caterpillars is highly variable. Specialist caterpillars such as the diamondback moth, Plutella xylostella, have gut-associated GSL acyl sulfatases that convert these compounds into nonhydrolyzable forms (Ratzka et al. 2002). The cabbage moth, Pieris rapae, caterpillars have gut-associated nitrile specifier proteins to convert GSL into less toxic nitriles instead of isothiocyanates (Heidel-Fischer et al. 2019). Therefore, specialist caterpillars that are capable of GSL stabilization or detoxification tend to prefer plants containing these compounds (Kliebenstein et al. 2002; Müller et al. 2010); arabidopsis with low GSL content is more susceptible to herbivory by generalist Spodoptera littoralis but not by specialist Pieris brassica caterpillars (Schlaeppi et al. 2008). Even so, GSLs may negatively affect specialist caterpillars. Aliphatic GSLs did not affect development of the specialist $P$. xylostella but did increase days to pupation of $P$. rapae caterpillars, producing smaller adults, which may negatively affect fecundity (Kimura and Tsubaki 1986; Kliebenstein et al. 2002; Kos et al. 2012; Mosleh Arany et al. 2008; Müller et al. 2010).

In contrast, less is understood about how generalist caterpillars, such as the beet armyworm, Spodoptera exigua (Hübner) (Lepidoptera: Noctuidae), or the cabbage looper, Trichoplusia ni (Hübner) (Lepidoptera: Noctuidae), cope with GSLs. Both these caterpillar species are considered to be generalists; however, $S$. exigua has a far broader plant host range compared with $T$. ni, which prefers to feed on GSL-containing brassicaceous crops (Howard et al. 1996; Pogue 2003; Robinson et al. 2010). When these caterpillars are fed GSLs, large amounts are excreted as toxic isothiocyanates (Jeschke et al. 2017). Arabidopsis lines that produce only aliphatic or indolic GSLs negatively affected growth and development but not mortality of two generalist caterpillars, S. littoralis and Mamestra brassicae; however, the impact of aliphatic GSLs was markedly more severe than indolic GSLs (Jeschke et al. 2017). Aliphatic GSLs slowed the growth of generalist $S$. exigua, $T$. ni, and the mulberry-specialist Manduca sexta caterpillars (Kliebenstein et al. 2002; Mosleh Arany et al. 2008; Müller et al. 2010), whereas indolic GSLs slowed S. exigua caterpillar development, with little effect on P. xylostella, T. ni, or M. sexta (Müller et al. 2010). Thus, it appears that generalist caterpillars have weaker mechanisms to detoxify these specific compounds and may have other mechanisms to avoid jasmonateassociated induced plant defenses, such as through activation of phytohormone pathways that interfere with jasmonateresponsive gene expression (Acevedo et al. 2015).

Feeding behavior and caterpillar-derived effectors recognized by the plant alter induced defense responses (Acevedo et al. 2015; Basu et al. 2018; Bown et al. 2002). GSLs may affect caterpillar feeding behavior (Schweizer et al. 2013; Shroff et al. 2008), although it is not clear if this difference then affects GSL levels. In terms of the effects of caterpillar-derived compounds on plant defenses, much attention has focused on caterpillar regurgitant and salivary effectors. Caterpillar regurgitant originates from the insect gut and has been shown to contain effectors such as fatty acid-amino acid conjugates (FACs) and ATP synthase-derived inceptins (Acevedo et al. 2015; Basu et al. 2018). If the caterpillar regurgitates while feeding (Peiffer and Felton 2009), secreted FACs are detected by the plant and activate JA accumulation (Hettenhausen et al. 2015). Inceptins, regurgitant-associated peptides derived from the plant chloroplast ATP synthase, upon recognition by the plant induce SA, JA, and ethylene production (Schmelz et al. 2006). FACs and inceptins are assumed to occur widely across caterpillar species (Schmelz et al. 2006, 2012; Yoshinaga et al. 2010).

Caterpillar labial salivary effectors have been widely studied because of their reported suppression of induced plant defenses (Acevedo et al. 2015), although there are examples of caterpillar saliva positively eliciting defenses in tomato (Louis et al. 2013; Tian et al. 2012). Labial saliva of S. exigua caterpillars interferes with jasmonate-responsive induced defense of arabidopsis and the legume Medicago truncatula (Bede et al. 2006; Lan et al. 2014; Paudel and Bede 2015; Paudel et al. 2013; Weech et al. 2008). In particular, caterpillar labial saliva-associated glucose oxidase (GOX) that catalyzes the production of hydrogen peroxide $\left(\mathrm{H}_{2} \mathrm{O}_{2}\right)$ may activate pathways, such as SA- or ethylene-responsive signaling pathways, that modulate jasmonate-dependent responses (Černý et al. 2018; Chamnongpol et al. 1998; Desikan et al. 2005; León et al. 1995; Mhamdi et al. 2010; Mittler et al. 2011; RobertSeilaniantz et al. 2011; Vanderauwera et al. 2005). S. exigua caterpillars are known to secrete GOX in their labial saliva (Paudel et al. 2013); however, this enzyme could not be detected in $T$. $n i$ saliva (Rivera-Vega et al. 2018). In contrast, catalase, an enzyme that catalyzes the decomposition of $\mathrm{H}_{2} \mathrm{O}_{2}$ to oxygen and water, was identified in $T$. $n i$ caterpillar labial saliva (Rivera-Vega et al. 2018).

Generalist caterpillars may have strategies to manipulate general plant signaling pathways to attenuate defense responses through phytohormone crosstalk (Basu et al. 2018). Particularly, caterpillar salivary effectors may activate plant signaling pathways, such as the SA pathway, to suppress the jasmonateresponsive network (Acevedo et al. 2015). T. ni and S. exigua caterpillars are both classified as generalists, but $T$. $n i$ caterpillars have a more restricted plant host preference (Howard et al. 1996; Pogue 2003; Robinson et al. 2010). These two species also differ in their salivary effectors, with $S$. exigua possessing GOX, which generates $\mathrm{H}_{2} \mathrm{O}_{2}$ that may activate $\mathrm{SA}$ signaling, and $T$. $n i$ having a catalase that degrades this product (Paudel et al. 2013; RiveraVega et al. 2018; Weech et al. 2008). In this study, temporal 
patterns of phytohormones, gene expression, and GSL profiles were compared in arabidopsis rosette leaves in response to three treatments - mechanical wounding or chewing damage by caterpillars of either the beet armyworm, S. exigua, or the cabbage looper, $T . n i$ - to further understand how generalist caterpillars undermine plant defense responses, which will enhance our knowledge for the development of sustainable agricultural pest management strategies.

\section{MATERIALS AND METHODS}

\section{Insect maintenance}

Beet armyworm (S. exigua) eggs were initially purchased from Frontier Agricultural Sciences (Newark, DE) and are maintained in the Bede laboratory. Cabbage looper (T. ni) eggs were purchased from the Canadian Forest Service (Ottawa, ON, Canada). The two colonies were reared in a growth cabinet $(16 \mathrm{~h} / 8 \mathrm{~h}$ light/dark; 28 to $40 \%$ relative humidity; $28.5^{\circ} \mathrm{C}$ ), and caterpillars were maintained on a wheat germ-based artificial diet (Bio-Serv, Flemington, NJ). Both caterpillar species typically have five instars (personal observation). After pupation, adult moths were transferred to jars and allowed to mate. T. $n i$ moths were given a sugar solution of $1 \mathrm{mg} / \mathrm{ml}$ of ascorbic acid, $0.5 \mathrm{~g} / \mathrm{ml}$ of sucrose, $50 \mathrm{mg} / \mathrm{ml}$ of honey, and $10 \mathrm{mg} / \mathrm{ml}$ of methyl paraben (prepared in ethanol) (Ebling and Dedes 2015). Eggs were collected to maintain the colony.

For the experiments, fourth-instar caterpillars were used. Caterpillars were allowed to feed on arabidopsis plants for at least $6 \mathrm{~h}$ and then starved for a maximum of $1 \mathrm{~h}$ before the experiment.

\section{Plant maintenance}

A. thaliana ecotype Columbia (Col-0) seeds were obtained from the Arabidopsis Biological Resource Center (no. CS3749). Seeds were sterilized with $0.525 \%$ bleach $(\mathrm{NaOCl}$ ) (for $5 \mathrm{~min}$ ) and $70 \%$ ethanol (for $2 \mathrm{~min}$ ); after rinsing in sterile $\mathrm{dH}_{2} \mathrm{O}$ three times, they were plated on Murashige and Skoog medium plates, $0.8 \%$ agar, and stratified for 3 days $\left(4^{\circ} \mathrm{C}\right.$ in the dark) to synchronize seed germination. Plates were transferred to a phytorium growth cabinet (light intensity $140 \mu \mathrm{mol} \mathrm{m} \mathrm{m}^{-2} ; 16 \mathrm{~h} / 8 \mathrm{~h}$ light/dark; $22^{\circ} \mathrm{C}$ ). After germination, 1-week-old seedlings were transplanted into potting mixture (Agromix G6, Fafard). Three seedlings were planted in each round pot $(12 \mathrm{~cm}$ diameter $\times 11 \mathrm{~cm}$ height $)$. As needed, approximately three times per week, plants were watered with dilute $N: P: K$ fertilizer (20-20-20, $1 \mathrm{~g} / 7$ liters of water).

The 4-week-old plants used in the experiment were at the vegetative stage and approximately at the 3.7 growth stage as defined by Boyes et al. (2001).

\section{Experimental design}

Three independent experiments were performed: experiment 1 , mechanical damage; experiment 2, T. ni herbivory; and experiment 3, S. exigua herbivory. Each experiment was temporally repeated at least three times. Three days before the experiment, the plants in each pot were enclosed in a plastic chamber (2-liter polyethylene terephthalate soft drink bottles with the top and bottom removed) to form a cage to allow the caterpillars to feed ad libitum but not escape. Right before the experiment, a Plexiglas shield was placed between the control (untreated) plants and treatment plants (wounding or herbivory) to prevent volatiles from wounded plants affecting controls.

At 9 P.M. (time 0), treatment plants were either wounded or caterpillars added to the pot. For mechanical wounding, a hole punch was used to wound every fully expanded rosette leaf without damaging the midvein. For herbivory experiments, T. $n i$ (fourth instar, six caterpillars per pot) or S. exigua (fourth instar, two caterpillars per pot) were added to the plants for $12 \mathrm{~h}$ ( 9 A.M., $12 \mathrm{~h}$ timepoint), at which time they were removed from all plants. Three pots of control and treatment (wounding, caterpillar) plants were used to estimate biomass loss due to treatment.

At 9:00 A.M. (12 h timepoint), six pots containing three arabidopsis plants per pot were randomly selected (Table 1). From three of these pots, two wounded leaves were taken from each plant and pooled (six leaves pooled from three pots $=$ three biological samples) and immediately frozen in liquid nitrogen $\left(\mathrm{N}_{2}\right)$ for the analyses of gene expression. From the other three pots, whole rosettes from the nine plants were pooled and frozen in $\mathrm{N}_{2}$ for phytohormone analyses (three plants per pot for three pots $=$ one biological sample). These samplings were repeated on new plants the next morning at 9:00 A.M. (36 h timepoint). At 9 P.M. (24 h timepoint), three new pots were randomly selected from the remaining plants. Two wounded leaves were taken from each plant and pooled (six leaves pooled from three pots $=$ three biological samples) for GSL analyses. At 9 P.M. the next day (48 $\mathrm{h}$ timepoint), the sampling process was repeated on new plants. Flash-frozen leaf samples were stored at $-80^{\circ} \mathrm{C}$ until analyses.

\section{Biomass loss}

At each temporal repetition $(\geq 3)$, one undamaged and one damaged plant were used to calculate biomass loss. The percentage biomass loss was determined from the dry weight percentage of damaged plant biomass divided by the undamaged plant biomass.

\section{GSL analyses}

Leaves of nine plants in the same temporal replicate were pooled to make one sample. The experiment was temporally repeated at least three times to have three (or more) experimental replicates. Samples were lyophilized, homogenized into a fine powder, and GSLs extracted followed by high-performance liquid chromatography (HPLC)-pulsed amperometric detection as described in Grosser and van Dam (2017). Briefly, GSLs were dissolved in $70 \%$ methanol, desulfated, and analyzed on an HPLC equipped with a photodiode array detector (Ultimate 3000 series system DAD-3000(RS), Thermo Fisher Scientific, Waltham, MA). Injection volume was set to $25 \mu$ l, and desulfated GSLs were separated on a reverse-phase $\mathrm{C}_{18}$ column (Acclaim 300 C18 column, $4.6 \times 150 \mathrm{~mm}, 300 \AA$ A $5 \mu \mathrm{m}$, Thermo Fisher Scientific) coupled with a $\mathrm{C}_{18}$ precolumn $(10 \times 4.6 \mathrm{~mm}, 5 \mu \mathrm{m}$ particle size) using an acetonitrile $(\mathrm{ACN}) /$ water gradient at a flow of $0.6 \mathrm{ml} / \mathrm{min}$ and a column temperature of $40^{\circ} \mathrm{C}$. The gradient profile started with an equilibration at $98 \% \mathrm{H}_{2} \mathrm{O}$ for $4.3 \mathrm{~min}$, followed by a gradient to $35 \% \mathrm{ACN}$ within $24.3 \mathrm{~min}$, with a hold until $29 \mathrm{~min}$ at $35 \%$ ACN. Thereafter the gradient went back to the initial $98 \%$ of $\mathrm{H}_{2} \mathrm{O}$ within $1 \mathrm{~min}$ and held the initial conditions for $10 \mathrm{~min}$. Desulfated GSLs were identified based on retention time and UV spectra compared with commercially available reference standards (Phytoplan Diehm \& Neuberger GmbH, Heidelberg, Germany). GSLs were quantified at $229 \mathrm{~nm}$ using sinigrin as an external standard and response factors as described in Grosser and van Dam

TABLE 1

Sample collection times

\begin{tabular}{lccc}
\hline Time & Phytohormones & Gene expression & Glucosinolates \\
\hline Early & $12 \mathrm{~h}$ & $12 \mathrm{~h}$ & $24 \mathrm{~h}$ \\
Late & $36 \mathrm{~h}$ & $36 \mathrm{~h}$ & $48 \mathrm{~h}$ \\
\hline
\end{tabular}


(2017). Data were processed using Thermo Scientific Chromeleon Chromatography Data System software (version 7.2 SR5 MUa (9624), Thermo Fisher Scientific).

\section{Phytohormone analysis}

The acidic phytohormone profile of arabidopsis rosettes was measured by ultraHPLC-triple quadrupole mass spectrometry (UHPLC-EVOQ-TQ-MS, Bruker) as per Martinez Henao et al. (2020). Briefly, lyophilized samples were finely ground by a TissueLyser II (Qiagen) and extracted in ethyl acetate (MS grade) containing a mixture of isotopically labeled standards of D6-JA and D6-JA-Ile (HPLC standards), D4-SA, and D6-ABA (OlChemIm s.r.o.). After vigorous vortexing (10 min), samples were centrifuged $\left(18,994 \times g\right.$ for $\left.10 \mathrm{~min}, 4^{\circ} \mathrm{C}\right)$ and the supernatant transferred to a new tube. Extraction was repeated and the supernatants pooled, followed by evaporation of the solvent using a vacuum concentrator at room temperature. The pellet was fully resuspended in 70\% methanol (HPLC-MS grade). A final centrifugation step $(18,994 \times g$ for $10 \mathrm{~min}$, $4^{\circ} \mathrm{C}$ ) was performed to ensure all nonsoluble debris was removed.

Metabolites were separated by reverse-phase UHPLC on a $\mathrm{C}_{18}$ column (Zorbax Extend, $4.6 \times 50 \mathrm{~mm}, 1.8 \mu \mathrm{m}$; column temperature $42^{\circ} \mathrm{C}$ ). After an isocratic 5\% ACN (HPLC-MS grade) containing $0.05 \%$ formic acid gradient for $30 \mathrm{~s}$, the ACN levels were increased to $50 \% \mathrm{ACN}, 0.05 \%$ formic acid over $2 \mathrm{~min}$, which then remained stable for $1 \mathrm{~min}$ before returning to initial conditions over $1 \mathrm{~min}$. After separation, compounds were put into gaseous phase by electron spray ionization under the following conditions: capillary voltage $4,500 \mathrm{~V}$, cone 35 arbitrary units (a.u.) $/ 350^{\circ} \mathrm{C}$, probe 60 a.u./ $475^{\circ} \mathrm{C}$, nebulizer gas $\left(\mathrm{N}_{2}\right) 60$ a.u. Compounds were identified based on retention time (comparison with standards), and transition $\mathrm{m} / \mathrm{z}$ and amount were calculated based on peak area of corresponding internal standard and initial sample weight.

\section{RNA extraction and CDNA synthesis}

RNA samples were prepared from three temporal repetitions, each consisting of three pooled biological replicates. Samples were ground with a sterilized mortar and pestle in liquid nitrogen. Total RNA was extracted using EZ-10 Spin Column Plant RNA Minipreps Kit (Bio-Basic) following manufacturer instructions. Lysis buffer was added to $\sim 50 \mathrm{mg}$ of finely ground plant tissue, followed by vigorous vortexing, incubation at room temperature for $5 \mathrm{~min}$, and centrifugation $(12,000 \times g, 30 \mathrm{~s}$, room temperature). An aliquot of supernatant was transferred to a sterile $1.5-\mathrm{ml}$ centrifuge tube, half volume of ethanol was added, and the tube was gently mixed by inversion. The solution was transferred to a filter-based spin column. After centrifugation $(12,000 \times g$ for $30 \mathrm{~s}$ at room temperature) and discarding the flow-through, there were two additional wash steps (Universal GT Solution followed by Universal NT solution); after addition of each wash solution, the samples were centrifuged and the flow-throughs discarded. The column was placed in a fresh $1.5-\mathrm{ml}$ centrifuge tube. RNase-free water was added. After incubation of 2 min at room temperature, total RNA was eluted by centrifugation $(12,000 \times g$ for $30 \mathrm{~s}$ at room temperature $)$.

Total RNA was treated with DNase (1U), and the absence of genomic DNA was confirmed by polymerase chain reaction (PCR)based amplification using primers that span an intronic region 5' -ATGGGTCGTCATCAGATTCAGAGCAGATAA-3' and 5'CATATAAGAGGTGTGTTAGAGACAATAATA-3' as conducted in Weech et al. (2008). RNA concentration $\left(\mathrm{OD}_{260} / \mathrm{OD}_{280}\right)$ and purity $\left(\mathrm{OD}_{260} / \mathrm{OD}_{230}\right)$ were measured using the infinite $\mathrm{M} 200$ Pro microplate reader (Tecan), and quality was checked by electrophoresis on 1\% TAE-based bleach gel (Aranda et al. 2012). Three clear bands representing 28S ribosomal RNA (rRNA), 18S rRNA, and 5S RNA were present. One microgram of total RNA was used as the template to generate cDNA using the QuantiTect Reverse Transcription Kit (Qiagen) following the manufacturer's instructions. After incubation at $42^{\circ} \mathrm{C}$ for $2 \mathrm{~min}$, Quantiscript RT buffer, RT primer mix, and Quantiscript reverse transcriptase were added to the sample and the mixture incubated at $42^{\circ} \mathrm{C}$ for $15 \mathrm{~min}$. After the reverse transcription reaction was complete, samples were incubated at $95^{\circ} \mathrm{C}$ for $3 \mathrm{~min}$ to inactivate the reverse transcription enzyme. cDNAs were stored at $-20^{\circ} \mathrm{C}$.

Gene expression. Gene-specific primers were identified from the literature and reaction conditions optimized to ensure that standard curves (50 fg to $500 \mathrm{ng}$ ) had an amplification efficiency between 90 and $110 \%$ (Supplementary Table S1). Quantitative real-time PCR (qRT-PCR) was optimized for each primer set by adjusting annealing temperatures and/or primer concentrations so that the efficiency of amplification for a standard curve was between 90 and $110 \%$. Dissociation curves generated using a continuous scan from 60 to $95^{\circ} \mathrm{C}$ that showed a sharp peak at the melting temperature of the amplicon confirmed amplicon purity. Amplicons were sent for sequencing to ACGT Corporation to verify accuracy.

qRT-PCR reactions were conducted in white 96-well PCR plates (Thermo Scientific). On each plate, three replicates of every biological replicate were analyzed. Each well contained 1× Greento-Go qPCR Low ROX Mastermix (Bio-Basic), $500 \mathrm{nM}$ each of forward and reverse primers, $100 \mathrm{ng}$ of cDNA (1:10 dilution), and RNase-free water. Nontemplate controls were included. Amplification was conducted using a Mx3000p (Stratagene) with the following conditions: $95^{\circ} \mathrm{C}$ for $10 \mathrm{~min}$, followed by 40 cycles of $95^{\circ} \mathrm{C}$ for $15 \mathrm{~s}$, annealing temperature (Supplementary Table S1) for $60 \mathrm{~s}$, and $72^{\circ} \mathrm{C}$ for $30 \mathrm{~s}$. Two technical plate replicates were performed. The threshold was automatically set by the Mx3000 software (Stratagene). Relative quantification was performed through $\delta-\delta C_{T}$ analysis and relative to the geometric mean of three reference genes (AtACT2, AtCBP20, and AtUnk [Supplementary Table S1]).

Statistical analysis. All experiments were repeated temporally at least three times. Plants were never sampled twice. Outliers were detected by the maximal normed residual test and removed (Stefansky 1971). Biomass data were compared by one-factor analysis of variance (ANOVA) using the statistical software SPSS version 16 (IBM). Phytohormone, gene expression, and GSL data were compared by two-factor ANOVA (treatment and time). Significant differences were identified by Tukey honest significant different post hoc tests (Supplementary Tables S2 to S4). Phytohormone and GSL data that violated Levene's test of homogeneity were normalized by $\log _{10}$.

\section{RESULTS}

\section{Biomass loss}

To ensure that the amount of damage by each treatment was similar, biomass loss due to the different treatments, mechanical wounding or herbivory by $T$. $n i$ or $S$. exigua caterpillars, was determined (Supplementary Fig. 1). Biomass loss through mechanical removal or caterpillar herbivory ranged between 22 and $25 \%$ and was similar over all treatments.

\section{Phytohormones}

Plant responses to caterpillar herbivory are influenced by phytohormone-mediated signaling networks that integrate physiological and environmental information to shape the final outcome. In response to caterpillar herbivory or recognition of necrotrophic pathogens, jasmonates primarily mediate induced 
defense responses but are influenced by ethylene-, ABA-, and SA-responsive pathways through multiple signaling nodes (Broekgaarden et al. 2015; Caarls et al. 2015; Pieterse et al. 2012; Robert-Seilaniantz et al. 2011). Principal component analysis (PCA) illustrates the dynamics of phytohormone response to the different treatments (Fig. 1). Both at 12 and $36 \mathrm{~h}$ posttreatment, the hormonal profile of herbivore-damaged plants clearly separated from those of control and wounded plants. The wound response, which mainly reflects the change in jasmonate hormones, is less strong and is transient; the hormone profiles of wounded and control plants are distinct at $12 \mathrm{~h}$ but overlap at $36 \mathrm{~h}$. Finally, the initial response to both herbivores is similar but diverges at the later timepoint.

When looking in more detail at individual signaling pathways, we found that foliar ABA levels increased in response to caterpillar herbivory but not in response to mechanical damage (Fig. 2). A similar pattern was observed in SA levels (Fig. 3A). However, SA levels remained elevated in $T$. $n i$-attacked plants but returned to basal levels at $36 \mathrm{~h}$ in $S$. exigua-infested plants (Fig. 3B and C). It is of interest that the expression of the SA-/ NPR1-dependent gene AtPRl was only induced in response to $S$. exigua herbivory (Fig. 3D to F) (Ramírez et al. 2010). In contrast, expression of the SA-dependent NPR1-independent gene AtNAC102 was not observed in response to any treatment over the time points selected (Fig. 3G to I) (Blanco et al. 2005).
The jasmonate-related phytohormones, OPDA, JA, and JA-Ile, were induced upon damage (mechanical wounding, caterpillar herbivory) (Figs. 4A to $\mathrm{C}, 5 \mathrm{~A}$ to $\mathrm{F}$ ). OPDA levels were higher in caterpillar-damaged plants at $36 \mathrm{~h}$ compared with $12 \mathrm{~h}$ postfeeding, and this pattern was not observed in mechanically wounded plants (Fig. 4A to C); this difference in temporal dynamics may reflect the plant response to continual wounding stress over the first $12 \mathrm{~h}$ that it received when caterpillars fed on the leaves.

The OPDA- and ABA-responsive signaling marker AtZAT10 is involved in chloroplast-to-nucleus stress signaling (Arnold et al. 2016; Mittler et al. 2006; Rossel et al. 2007; Sakamoto et al. 2004; Taki et al. 2005). This zinc finger transcription factor is a modulator of plant stress responses, both activating as well as negatively regulating the response to tailor the response to the stress (Mittler et al. 2006). Even though $T$. ni or $S$. exigua caterpillar herbivory elicited similar OPDA and ABA profiles, induction of AtZAT10 was only observed in $T$. ni-damaged plants (Fig. 4D to F). In contrast, Rehrig et al. (2014) observed induced AtZAT10 expression $24 \mathrm{~h}$ postinfestation with $S$. exigua caterpillars or wounding but not by herbivory with specialist $P$. rapae caterpillars.

A robust jasmonate increase was observed in response to mechanical or chewing insect damage (Fig. 5A to F). Changes in the expression of jasmonate-responsive genes also reflected input from phytohormonal network crosstalk (Caarls et al. 2015). At the time points selected, AtLOX2 expression, a jasmonate-responsive, MYC2-dependent gene
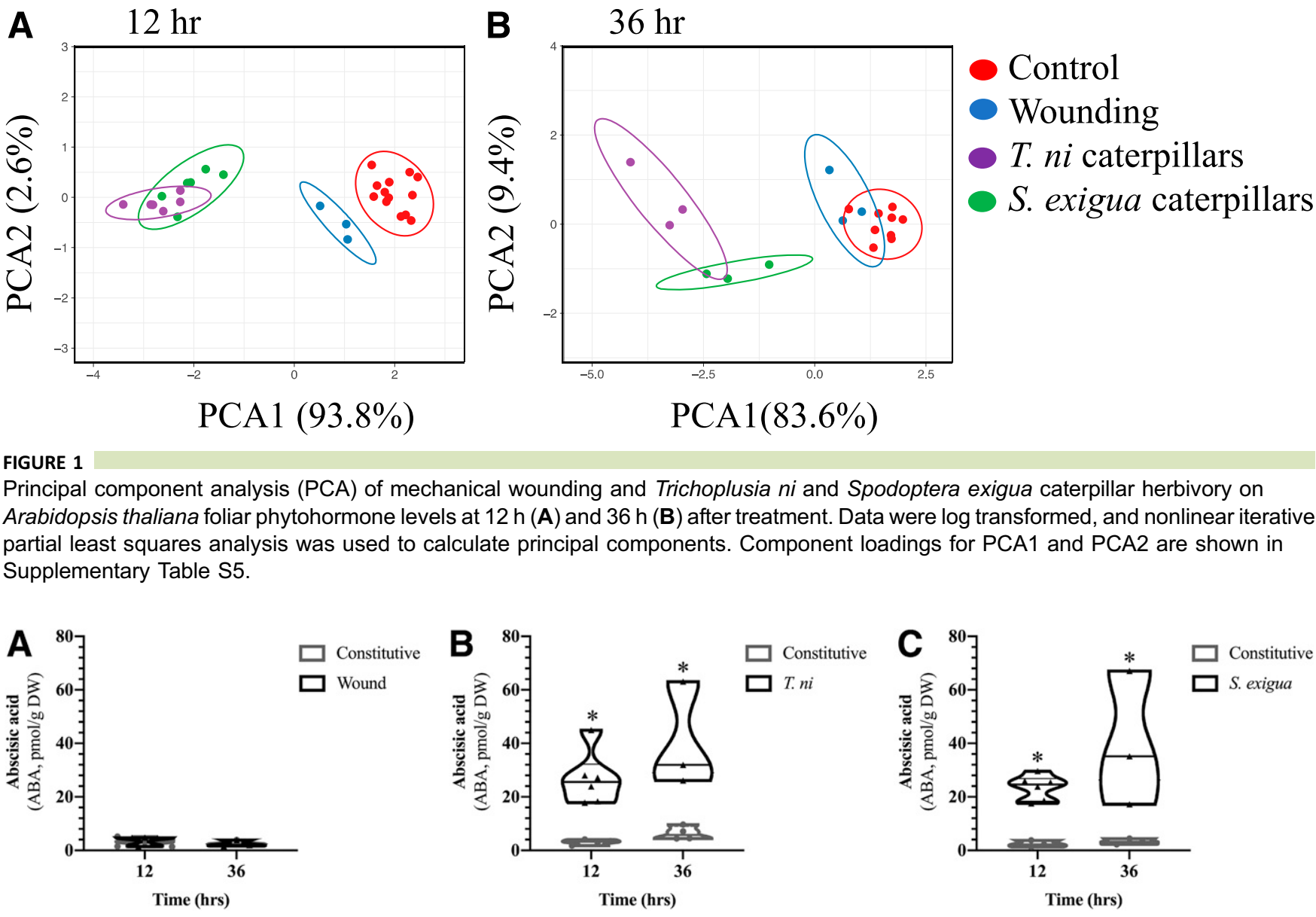

FIGURE 1

Principal component analysis (PCA) of mechanical wounding and Trichoplusia ni and Spodoptera exigua caterpillar herbivory on Arabidopsis thaliana foliar phytohormone levels at $12 \mathrm{~h}(\mathbf{A})$ and $36 \mathrm{~h}(\mathbf{B})$ after treatment. Data were log transformed, and nonlinear iterative partial least squares analysis was used to calculate principal components. Component loadings for PCA1 and PCA2 are shown in Supplementary Table S5.

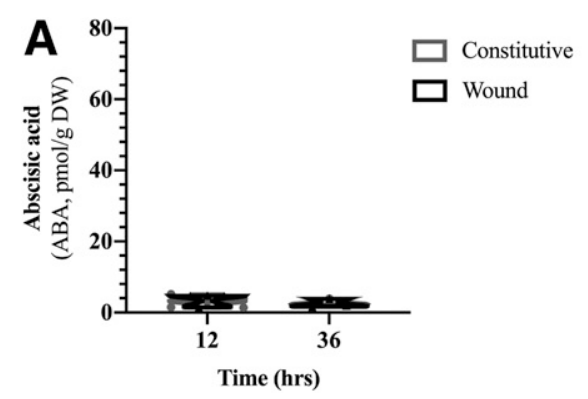

FIGURE 2

Abscisic acid (ABA) levels in Arabidopsis thaliana plants wounded mechanically or by herbivory by Trichoplusia ni or Spodoptera exigua caterpillars. Effect of mechanical damage (A) or herbivory by $T$. ni (B) or S. exigua (C) caterpillars on ABA levels. Data are represented by violin plots with the median indicated by a solid line. Significant differences were determined by two-factor analysis of variance (factors: time, treatment, time $\times$ treatment) (Supplementary Table S2). An asterisk $\left({ }^{*}\right)$ denotes induced levels significantly above constitutive levels. 
(Zhai et al. 2013), was only induced in response to $S$. exigua herbivory (Fig. 5G to I). Although AtLOX2 expression is induced by wounding and methyl jasmonate (Bell et al. 1995), continued JAmediated expression of jasmonate biosynthetic genes, such as AtLOX2, is often not observed (Scholz et al. 2015), suggesting a role for posttranslational modification in the regulation of JA biosynthesis. In support of this, Thivierge et al. (2010) noted that LOX2 is constitutively phosphorylated at $\operatorname{Ser}_{600}$ but dephosphorylated in response to wounding or herbivory by caterpillars that had impaired labial salivary secretions.

The jasmonate-, MYC2-dependent induction of AtVSP2 expression is suppressed by ethylene or SA and enhanced by ABA (Anderson et al. 2004; Han et al. 2013; Lorenzo et al. 2004). AtVSP2 expression was induced in response to all treatments (Fig. $5 \mathrm{~J}$ to $\mathrm{L}$ ), for the most part reflecting the jasmonate phytohormone profile (Fig. 5A to F). In wounded plants, expression returned to basal levels at $36 \mathrm{~h}$, which is not observed in herbivore-attacked leaves. Because AtVSP2 jasmonate-induced expression is enhanced by ABA (Anderson et al. 2004), the elevated AtVSP2 levels at $36 \mathrm{~h}$ may reflect caterpillar herbivory-dependent continuance of jasmonate-responsive expression by ABA (Fig. 2).

The late gene AtPDF1.2 is synergistically induced through the jasmonate/ethylene pathway (Penninckx et al. 1996, 1998; Pré et al. 2008; Zarei et al. 2011). AtPDF1.2 expression is induced by T. $n i$ herbivory (Fig. $5 \mathrm{~N}$ ); in contrast, AtPDF1.2 expression is induced $12 \mathrm{~h}$ after $S$. exigua herbivory but returns to lower levels by $36 \mathrm{~h}$ (Fig. $5 \mathrm{M}$ to $\mathrm{O}$ ).

In contrast to AtPDF1.2, AtHEL/PR4 is an ethylene ORA59responsive but jasmonate COI1-independent gene (Penninckx et al. 1996; Potter et al. 1993; Pré et al. 2008). The expression of both genes is negatively regulated by $\mathrm{ABA}$ and $\mathrm{SA}$, but AtPDF 1.2 is negatively regulated through a SA/NPR1-dependent pathway, whereas AtHEL/PR4 is regulated through a SA/NPR1independent pathway (Anderson et al. 2004; Mur et al. 1996; Ndamukong et al. 2007). AtHEL/PR4 expression was only induced by caterpillar herbivory (Fig. 5P to R).
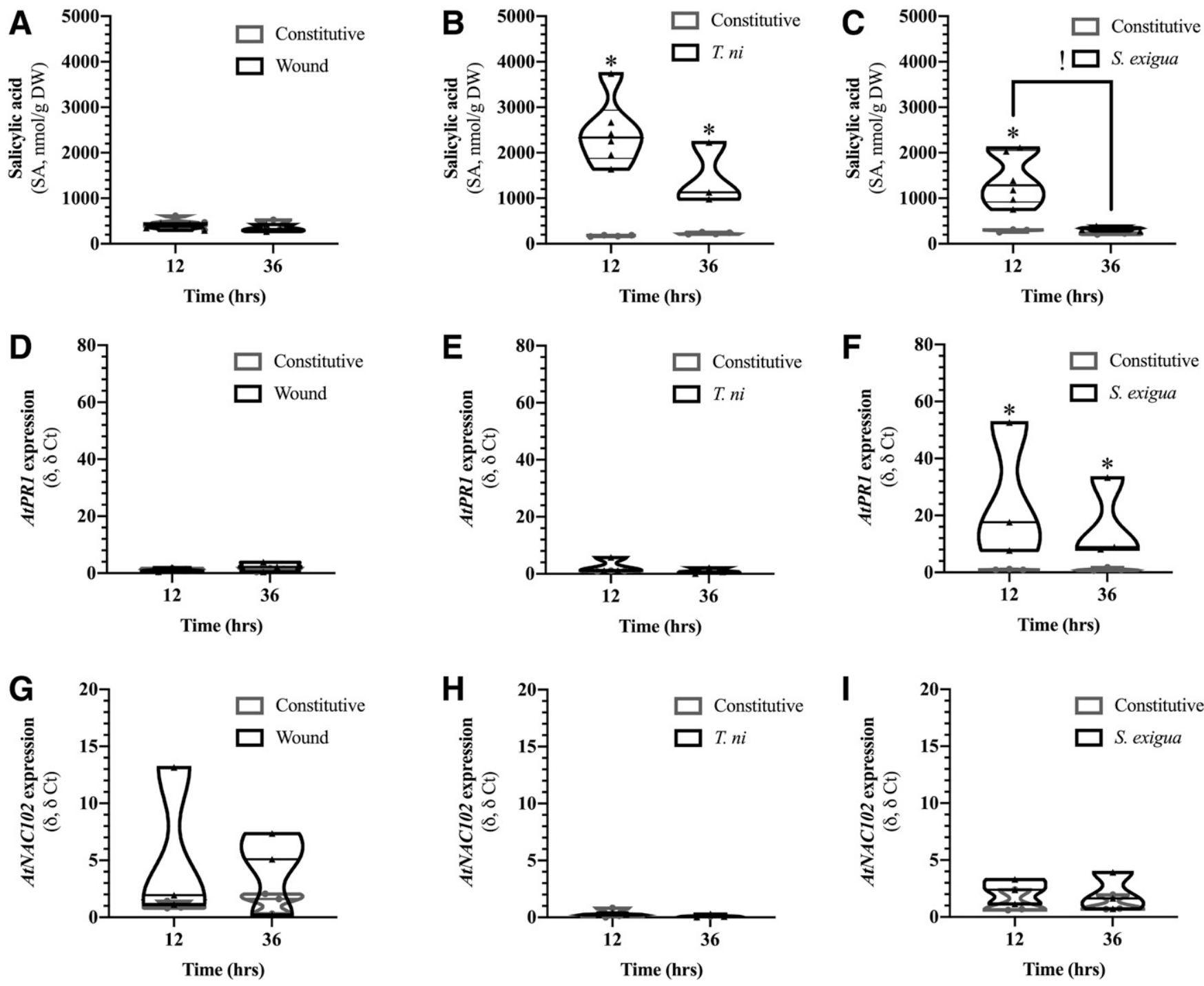

FIGURE 3

Salicylic acid (SA) levels and SA-responsive gene expression in Arabidopsis thaliana plants wounded mechanically or by herbivory by Trichoplusia ni or Spodoptera exigua caterpillars. Effect of mechanical damage (A, D, and G) or herbivory by T. ni (B, E, and H) or S. exigua (C, F, and I) caterpillars on SA levels (A to C), NPR1-dependent AtPR1 gene expression (D to F), and NPR1-independent AtNAC102 gene expression ( $\mathbf{G}$ to I). Data are represented by violin plots with the median indicated by a solid line. Significant differences were determined by two-factor analysis of variance (factors: time, treatment, time $\times$ treatment) (Supplementary Tables S2 and S3). An asterisk ( ${ }^{*}$ ) denotes induced levels significantly above constitutive levels. An exclamation mark (!) denotes a significant difference in induced levels between time points (12 versus $36 \mathrm{~h}$ ); time did not affect constitutive levels. 
GSLS

Aliphatic and indolic GSLs in arabidopsis leaves strongly contribute to plant protection against insect herbivory (Beekwilder et al. 2008; Hopkins et al. 2009; Howe and Jander 2008; Li et al. 2000; Mewis et al. 2005, 2006; Müller et al. 2010; Pangesti et al. 2016; Schlaeppi et al. 2008). Total GSLs as well as aliphatic and indolic total levels were not affected by wounding or herbivory by T. ni caterpillars (Fig. 6); in contrast, foliar levels of indolic GSLs increased in response to $S$. exigua caterpillar herbivory. Levels of specific GSLs were also affected by $S$. exigua, but not $T$. $n i$, caterpillar attack.

Foliar aliphatic GSL biosynthesis is transcriptionally regulated by the MYB transcription factors, AtMYB76 and, in particular, AtMYB28 and AtMYB29 (Beekwilder et al. 2008; Gigolashvili et al. 2007a, 2007b; Hirai et al. 2007). Foliar transcript expression of $A t M Y B 29$ or $A t M Y B 76$ did not change in response to wounding or caterpillar herbivory (Fig. 7D to I). However, AtMYB28 gene expression was induced in response to caterpillar herbivory (Fig. 7A to $\mathrm{C}$ ). In response to $S$. exigua caterpillar herbivory, induced transcript AtMYB76 levels fall at the 36-h time point but still remain elevated compared with constitutive levels (Fig. 7C). AtMYB28 regulates short-chain aliphatic GSL biosynthesis (Li et al. 2013). Twenty-four hours after $S$. exigua herbivory, levels of glucoerucin (ERU; C4 carbon chain GSL) increased and then fell to basal levels at $48 \mathrm{~h}$ (Fig. 7O). ERU is the thiol precursor of the sulfinyl form glucoraphanin (RAPH); as ERU levels decrease at $48 \mathrm{~h}$, there appears to be an increase in RAPH levels. S. exigua herbivory also induced foliar levels of the C8 GSL glucohirsutin (HIR) (Fig. 7U).
The transcription factors AtMYB34 and AtMYB51 regulate indole GSL biosynthesis (Frerigmann and Gigolashvili 2014). Treatments did not affect AtMYB51 expression, but AtMYB34 was induced in response to wounding or caterpillar herbivory (Fig. 8A to F). In response to T. ni herbivory, AtMYB34 expression rose within the first $12 \mathrm{~h}$ and then fell to near basal levels in the next $24 \mathrm{~h}$ (Fig. 8B). Therefore, it was unexpected that changes in foliar indole GSL levels were not observed in response to mechanical wounding or $T$. $n i$ feeding at the selected timepoints (Fig. 6). In comparison, AtMYB34 levels rose in $S$. exigua-infested plants and remained at high levels over the first $36 \mathrm{~h}$ (Fig. 8C); this was mirrored in foliar indolic GSL levels (Fig. 6), which primarily reflected glucobrassicin (GBC) (Fig. 8I). It is of interest that the indolic GSL neoglucobrassicin (1methoxyGBC) was present in $T$. $n i$ - and $S$. exigua-damaged plants $(0.070 \pm 0.015$ and $0.064 \pm 0.008 \mu \mathrm{mol} / \mathrm{g}$ dry weight, respectively), but this compound was not consistently detected in unwounded or mechanically damaged plants $(0.027 \pm 0.005$ and $0.027 \pm 0.003 \mu \mathrm{mol} / \mathrm{g}$ dry weight, respectively) (data not shown).

\section{DISCUSSION}

In brassicaceous plants, GSLs are the primary group of defensive compounds against insect herbivores (Beekwilder et al. 2008; Hopkins et al. 2009; Howe and Jander 2008; Li et al. 2000; Mewis et al. 2005, 2006; Müller et al. 2010; Pangesti et al. 2016; Schlaeppi et al. 2008). In general, aliphatic GSLs more negatively impact caterpillar herbivores than indolic GSLs (Beekwilder et al. 2008; Gigolashvili et al. 2007a, 2007b; Jeschke et al. 2017). As well, GSLs generally more negatively affect generalist
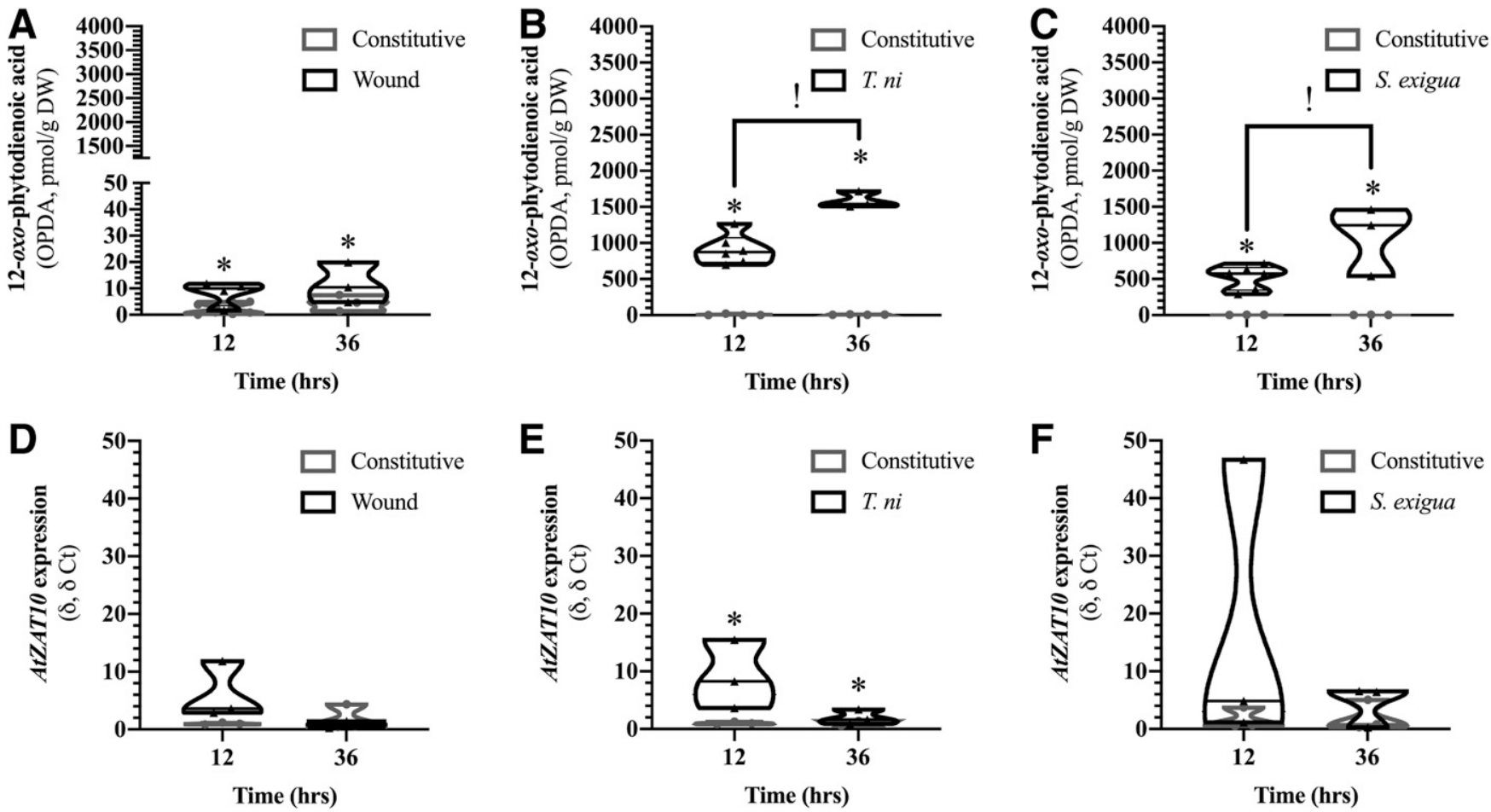

FIGURE 4

12-oxo-Phytodienoic acid (OPDA) and levels of the marker gene AtZAT10 in Arabidopsis thaliana plants wounded mechanically or by herbivory by Trichoplusia ni or Spodoptera exigua caterpillars. Effect of mechanical damage (A and D) or herbivory by T. ni (B and E) or S. exigua (C and F) caterpillars on OPDA levels (A to C) and AtZAT10 (D to F) gene expression. Data are represented by violin plots with the median indicated by a solid line. Significant differences were determined by two-factor analysis of variance (factors: time, treatment, time $\times$ treatment) (Supplementary Tables S2 and S3). An asterisk ( $\left.{ }^{*}\right)$ denotes induced levels significantly above constitutive levels. An exclamation mark (!) denotes a significant difference in induced levels between time points (12 versus $36 \mathrm{~h}$ ); time did not affect constitutive levels. 

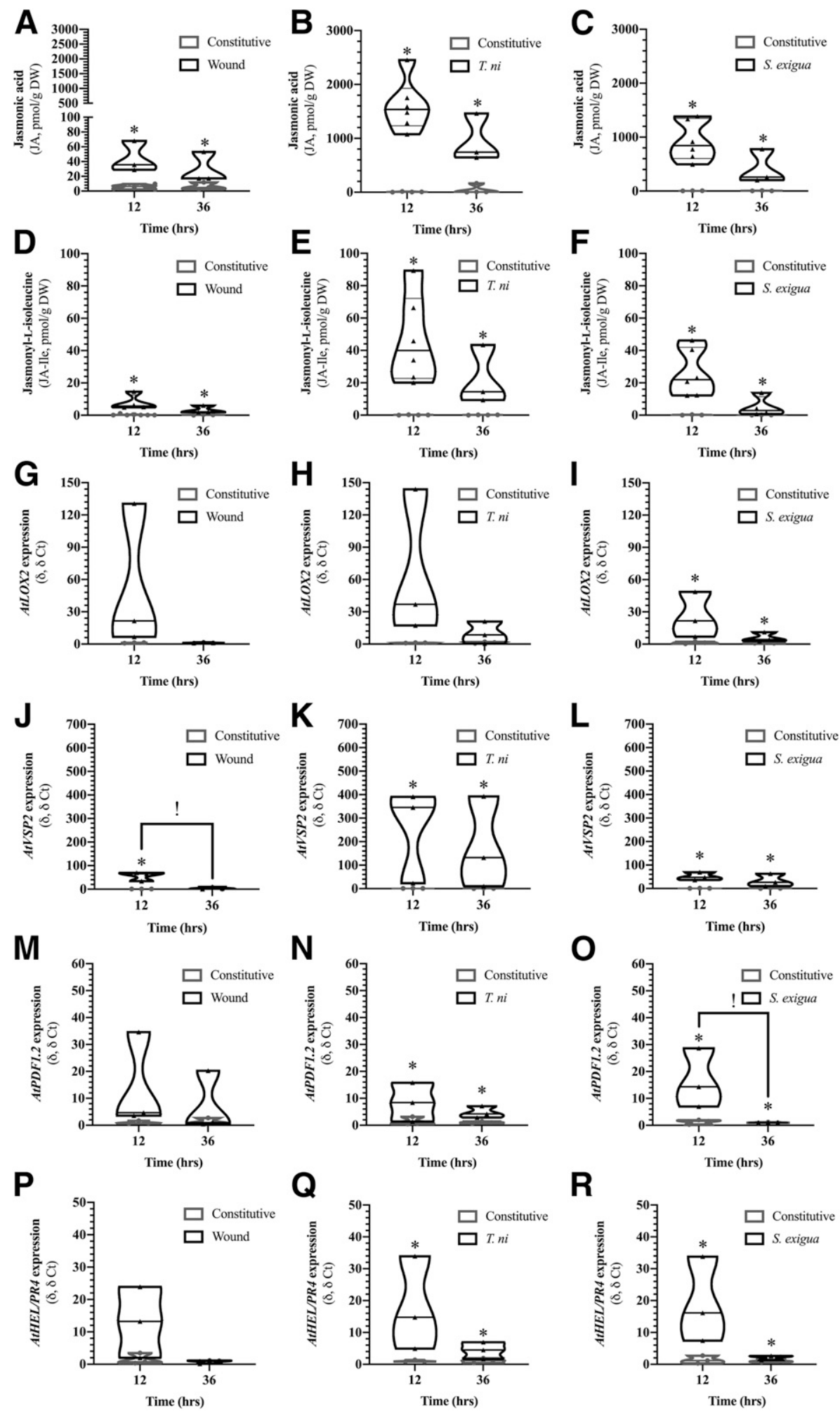

FIGURE 5

Jasmonate levels and jasmonate-responsive gene expression in Arabidopsis thaliana plants wounded mechanically or by herbivory by Trichoplusia ni or Spodoptera exigua caterpillars. Effect of mechanical damage (A, D, G, J, M, and P) or herbivory by T. ni (B, E, H, K, N, and Q) or S. exigua (C, F, I, L, O, and R) caterpillars on jasmonic acid (JA) levels (A to C), jasmonyl-L-isoleucine (JA-lle) levels (D to F), AtLOX2 gene expression ( $\mathbf{G}$ to $\mathbf{~ I ) , ~ A t V S P 2 ~ g e n e ~ e x p r e s s i o n ~ ( ~} \mathbf{J}$ to $\mathbf{L})$, AtPDF1.2 gene expression (M to $\mathbf{O}$ ), and AtHEL/PR4 gene expression (P to R). Data are represented by violin plots with the median indicated by a solid line. Significant differences were determined by two-factor analysis of variance (factors: time, treatment, time $\times$ treatment) (Supplementary Tables S2 and S3). An asterisk ( ${ }^{*}$ ) denotes induced levels significantly above constitutive levels. An exclamation mark (!) denotes a significant difference in induced levels between time points (12 versus $36 \mathrm{~h}$ ); time did not affect constitutive levels. 
caterpillars because specialists have evolved strategies to either prevent the conversion of ingested GSLs to more toxic forms or conjugate them to increase their excretion (Heidel-Fischer et al. 2019; Jeschke et al. 2017; Lambrix et al. 2001; Mewis et al. 2006; Ratzka et al. 2002; Schramm et al. 2012). Thus, a common strategy of generalist caterpillars, which may be exposed to a diverse range of plant specialized metabolites due to their wide dietary breadth, is to manipulate phytohormone pathways to minimize the major defensive pathway, through a process known as crosstalk (Acevedo et al. 2015; Ballaré 2011; Basu et al. 2018; Caarls et al. 2015; Howe et al. 2018). This study compared the phytohormone levels and marker gene expression and GSL profiles in response to two generalist caterpillars. Although there were similarities in plant responses, distinct caterpillar speciesspecific profiles are observed.

\section{Caterpillars and phytohormone pathways}

Strict comparison of plant responses between caterpillar herbivory and mechanical damage is hampered by the patchiness of insect feeding. Wound treatment was performed at time 0 , whereas caterpillars were allowed to feed for the first $12 \mathrm{~h}$ before their removal, therefore representing synchronous and asynchronous stress, respectively. As well, effectors in caterpillar oral secretions provide important information to modify plant responses (Acevedo et al. 2015; Basu et al. 2018). Even so, some generalizations between wounding and caterpillar feeding, as expected, are apparent.

Even though the total foliar damage was similar between treatments, caterpillar herbivory resulted in stronger, sustained phytohormone dynamics compared with mechanical wounding. At $36 \mathrm{~h}$ ( $24 \mathrm{~h}$ postremoval of insects), ABA and SA levels were elevated in response to caterpillar herbivory compared with wounded plants (Figs. 2A to C, 3A to C). Other studies did not find $S$. exigua herbivory-induced changes in foliar SA levels; Rehrig et al. (2014) and Weech et al. (2008) did not observe changes in foliar SA levels over the first 24 or $36 \mathrm{~h}$ after caterpillar herbivory, respectively. Levels of jasmonates, such as OPDA, JA, and JA-Ile, are elevated in mechanically damaged and caterpillar-damaged plants (Figs. 4A to C, 5A to F); foliar OPDA levels continued to increase over time in response to caterpillar herbivory compared with wounded plants (Fig. 4A to C).

Phytohormone profiles in response to herbivory were similar regardless of caterpillar species; however, the expression of AtPRl indicates that the SA-, NPR1-dependent pathway was activated in response to herbivory by $S$. exigua but not $T$. $n i$ caterpillars in the timeframe examined (Fig. 3B, C, E, and F).
Paudel et al. (2013) also noted a S. exigua caterpillar labial salivadependent induction of AtPRl gene expression, suggesting that one or more effectors in the salivary secretions are responsible for activating the SA/NPR1 pathway (Weech et al. 2008). Other studies have also shown that AtPRI is induced by $S$. exigua as well as $P$. rapae caterpillar herbivory (Mewis et al. 2006).

Insect herbivores activate signaling networks that enhance or attenuate plant responses to alter gene expression (Acevedo et al. 2015; Ballaré 2011; Basu et al. 2018; Caarls et al. 2015; Erb and Reymond 2019; Howe et al. 2018; Shigenaga and Argueso 2016). Therefore, phytohormone-responsive marker genes were used to deepen our understanding of caterpillar-mediated manipulation of plant induced responses. Jasmonate-responsive gene markers, AtLOX2, AtVSP2, AtHEL/PR4, and AtPDF1.2, show distinct expression profiles between wounding and caterpillar herbivory.

AtVSP2 expression is positively regulated by jasmonates and ABA through ORA47 but may also be negatively regulated through the SA/NPR1 and ethylene/ORA59 pathways (Anderson et al. 2004; Chen et al. 2016; Han et al. 2013; Lorenzo et al. 2004; Wang et al. 2008). Expression of AtVSP2 is induced in response to wounding and caterpillar herbivory (Fig. $5 \mathrm{~J}$ to $\mathrm{L}$ ); however, expression returns to basal levels at $36 \mathrm{~h}$ in mechanically damaged plants. This possibly reflects the higher ABA levels in caterpillar-infested plants that overrides antagonistic pathways to maintain enhanced gene expression (Fig. 2B and C). Similar induction of MYC2-dependent AtVSP2 expression occurs in response to herbivory by generalist caterpillars of Helicoverpa armigera, Helicoverpa zea, or M. brassicae or the specialist $P$. rapae (Pangesti et al. 2016; Verhage et al. 2011).

The jasmonate/ethylene-responsive markers AtPDF1.2 and AtHEL/PR4 are induced in response to caterpillar herbivory but not mechanical damage. Expression of AtHEL/PR4 may be antagonized by ABA or SA through an NPR1-independent route (Anderson et al. 2004; Ndamukong et al. 2007). The expression profile of AtHEL/PR4 reflects jasmonate levels in plants attacked by caterpillar herbivores; however, this relationship between jasmonate levels and AtHEL/PR4 expression is not observed in wounded plants (Fig. 5P to R). Similar results were also noted by Reymond et al. (2000), who observed induced AtHEL/PR4 expression in arabidopsis in response to herbivory by $P$. rapae but not mechanical damage. Mewis et al. (2006) also found that $P$. rapae and $S$. exigua caterpillar herbivory induced AtHEL/PR4 expression. This may reflect enhanced ethylene levels, which were not measured in our experiment, incurred by caterpillar herbivory over mechanical wounding that acts synergistically to jasmonates to increase AtHEL PR4 expression (O'Donnell et al. 1996); S. exigua herbivory
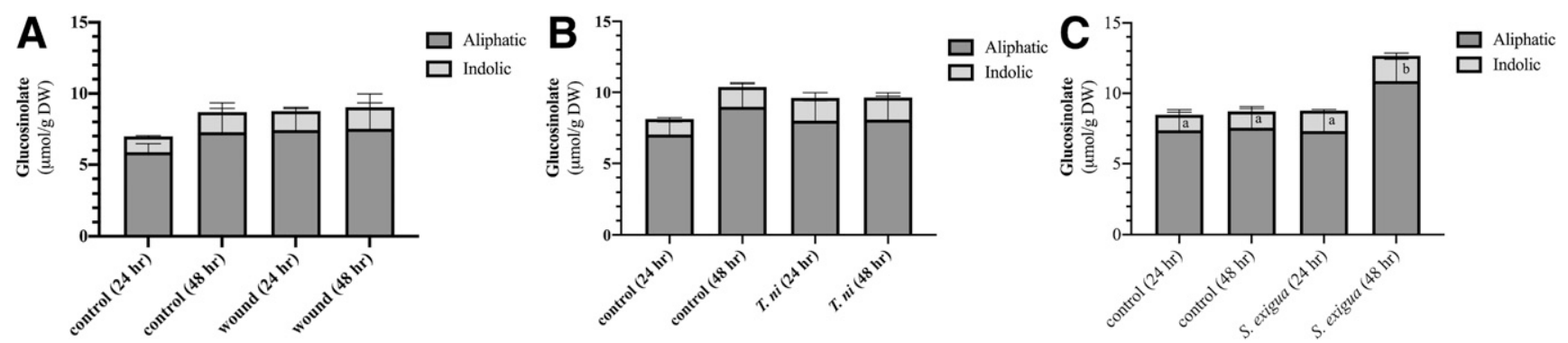

FIGURE 6

Glucosinolate (GSL) levels in Arabidopsis thaliana plants wounded mechanically or by herbivory by Trichoplusia ni or Spodoptera exigua caterpillars. Effect of mechanical damage $(\mathbf{A})$ or herbivory by T. ni (B) or S. exigua (C) caterpillars on GSL levels. Bars represent mean \pm the standard error. Significant differences were determined by two-factor analysis of variance and indicated by different alphabetical lettering (factors: time, treatment, time $\times$ treatment) (Supplementary Table S4). Herbivory by S. exigua caterpillars increased foliar indole GSL levels $(\mathrm{F}(3,14)=9.826 ; P=0.007)$. 

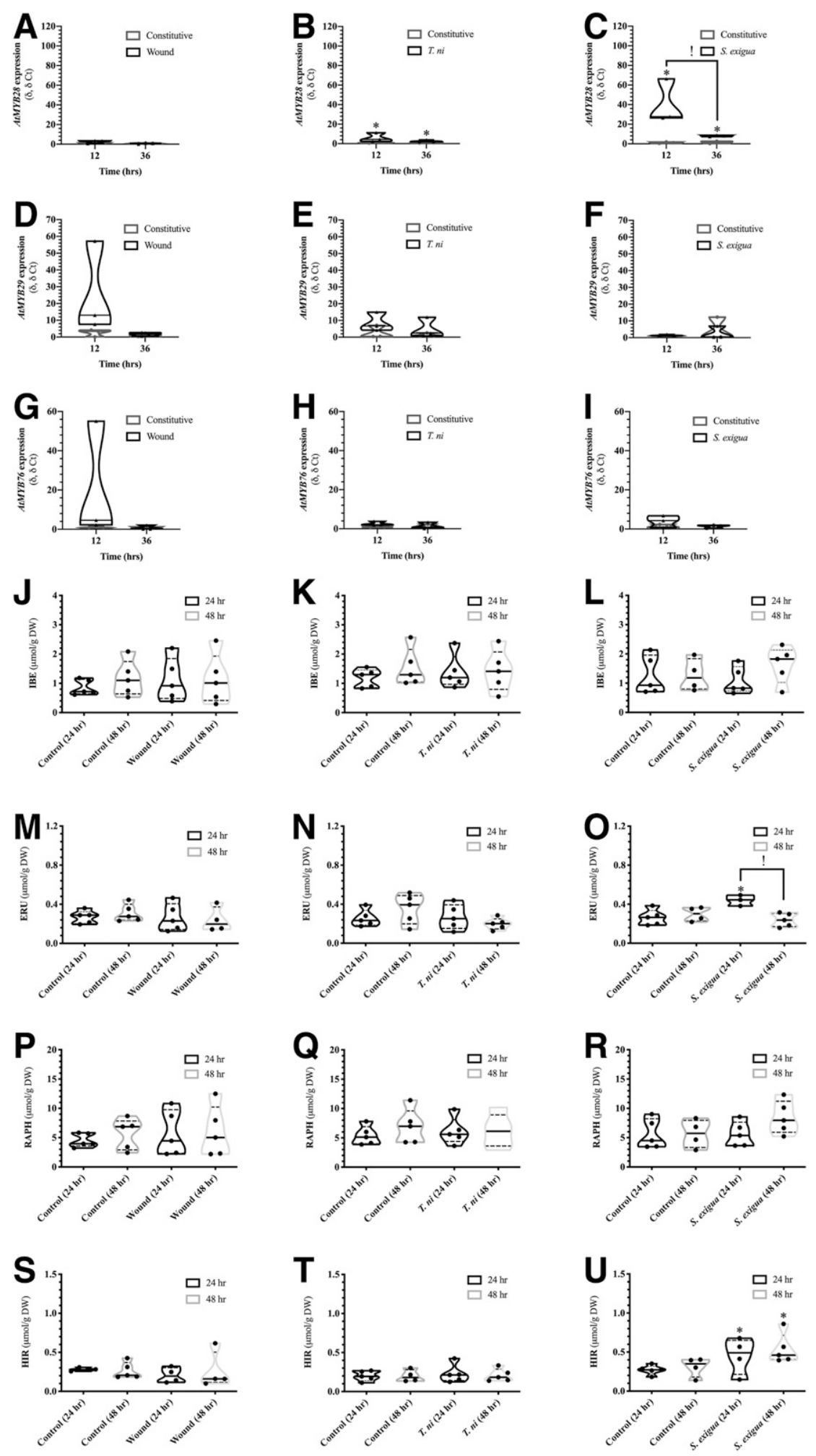

\section{FIGURE 7}

Aliphatic glucosinolate (GSL) biosynthesis transcription factor gene expression and aliphatic GSL levels in Arabidopsis thaliana plants wounded mechanically or by herbivory by Trichoplusia ni or Spodoptera exigua caterpillars. AtMYB transcription factors, AtMYB28, AtMYB29, and AtMYB76, regulate expression of genes that encode enzymes in aliphatic GSL biosynthesis. Effect of mechanical damage (A, D, G, J, M, P, and S) or herbivory by Trichoplusia ni (B, E, H, K, N, Q, and T) or Spodoptera exigua (C, F, I, L, O, R, and U) caterpillars on AtMYB28 (A to C), AtMYB29 (D to F), and AtMYB76 ( $\mathbf{G}$ to I) gene expression and levels of glucoiberin (IBE; 3-methylsulfinylpropyl GSL) ( $\mathbf{J}$ to $\mathbf{L}$ ), glucoerucin (ERU; 4-methylthiobutyl GSL) (M to O), glucoraphanin (RAPH; 4-methylsulfinylbutyl GSL) (P to R), and glucohirsutin (HIR; 8methylsulfinyloctyl GSL) (S to U). Data are represented by violin plots with the median indicated by a solid line and the interquartiles by dashed lines. Significant differences were determined by two-factor analysis of variance (factors: time, treatment, time $\times$ treatment) (Supplementary Tables S3 and S4). An asterisk (*) denotes induced levels significantly above constitutive levels. An exclamation mark (!) denotes a significant difference in induced levels between time points (12 versus $36 \mathrm{~h}$ ); time did not affect constitutive levels. 
increases foliar ethylene levels, and ethylene-responsive gene expression may be related to FACs present in the caterpillar regurgitant (Appel et al. 2014; Diezel et al. 2009, Rehrig et al. 2014). Transcriptional responses of arabidopsis to $T$. $n i$ herbivory also indicate activation of JA/ethylene pathways (Vogel et al. 2007). Given that ABA suppresses AtHEL/PR4 expression
(Anderson et al. 2004), the general foliar pattern of ABA and AtHEL/PR4 expression is compelling (Figs. 2, 5P to R).

Expression of the jasmonate/ethylene-responsive gene AtPDF1.2 is induced in response to caterpillar herbivory but falls by $36 \mathrm{~h}$ in $\mathrm{S}$. exigua-infested plants (Fig. $5 \mathrm{~N}$ and $\mathrm{O}$ ). This gene is negatively regulated by ABA and SA in NPR1-dependent or
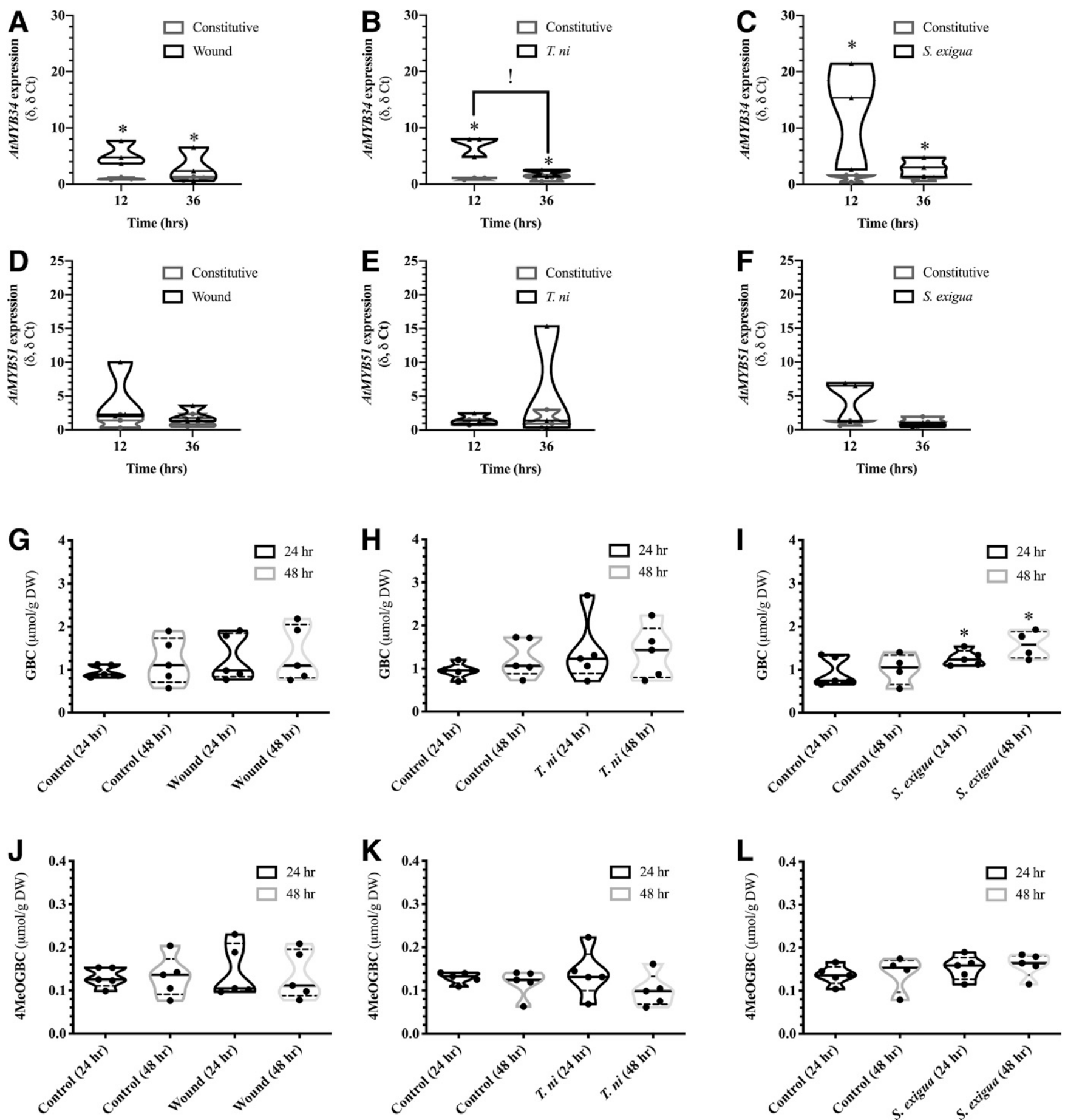

FIGURE 8

Indole glucosinolate (GSL) biosynthesis transcription factor gene expression and indole GSL levels in Arabidopsis thaliana plants wounded mechanically or by herbivory by Trichoplusia ni or Spodoptera exigua caterpillars. Effect of mechanical damage (A, D, G, and J) or herbivory by T. ni (B, E, H, and K) or S. exigua (C, F, I, and L) caterpillars on AtMYB34 (A to C) and AtMYB51 (D to F) gene expression and levels of glucobrassicin (GBC; indol-3-ylmethyl GSL) (G to I) and 4-methoxyglucobrassicin (4MeOGBC; 4-methoxyindoyl-3-yl GSL) (J to L). Data are represented by violin plots with the median indicated by a solid line and the interquartiles by dashed lines. Significant differences were determined by two-factor analysis of variance (factors: time, treatment, time $\times$ treatment) (Supplementary Tables S3 and S4). An asterisk $\left({ }^{*}\right)$ denotes induced levels significantly above constitutive levels. An exclamation mark (!) denotes a significant difference in induced levels between time points (12 versus $36 \mathrm{~h}$ ); time did not affect constitutive levels. 
-independent pathways that reflect ethylene levels (Caarls et al. 2015; Leon-Reyes et al. 2009, 2010a, 2010b; Spoel et al. 2003; Van der Does et al. 2013). It is unlikely that this differential expression between caterpillars is related to ABA-mediated suppression, because foliar ABA levels are induced by herbivory by both species of caterpillars (Fig. 2B and C). Therefore, this differential AtPDF1.2 expression observed in response to the two different caterpillar species is likely mediated by SA-dependent antagonism that occurs on many different regulatory levels (Caarls et al. 2015). In response to elevated SA levels, expression of glutaredoxin 480 (GRX480) is dependent on the NPR1 pathway (La Camera et al. 2011; Ndamukong et al. 2007). GRX480 binds to TGA transcription factors in the promoter of AtPDF1.2 to interfere with JA-mediated expression (Zander et al. 2012). The expression pattern of the SA NPR1-responsive gene AtPRl in response to $S$. exigua herbivory indicates that this signaling pathway is only induced in response to these caterpillars and, therefore, may be responsible for the suppression of AtPDF1.2 expression (Figs. 3E and F, 5N and O) (Ramírez et al. 2010). This supports previous observations that $S$. exigua-mediated suppression of AtPDF1.2 is mediated through a SA/NPR1- and TGA transcription factor-dependent mechanism and reflects effectors in the caterpillar labial saliva that are proposed to activate this pathway, although we cannot discount the involvement of the ethylene pathway (Paudel and Bede 2015; Paudel et al. 2013; Weech et al. 2008). However, previous studies have found a biphasic increase in AtORA59 levels in plants attacked by $S$. exigua caterpillars (Rehrig et al. 2014), supporting an ethyleneindependent mechanism of SA suppression of AtPDF1.2.

Both this study and Rehrig et al. (2014) compared arabidopsis phytohormone-related defense responses to $S$. exigua caterpillars. These two studies differ on a few observations, namely, caterpillar-associated changes in SA and AtZAT10 gene expression (Figs. 3B and C, 4E and F). This may reflect differences in daylength used between these two studies. Daylength is known to affect induced defense responses in arabidopsis, a facultative long-day plant (Burow and Halkier 2017; Mouradov et al. 2002). Rehrig et al. (2014) grew their plants under short day conditions $(8 \mathrm{~h} / 16 \mathrm{~h}$ light/dark) in comparison with this study $(16 \mathrm{~h} / 8 \mathrm{~h})$, which was chosen to reflect summer daylength in Canada.

\section{Caterpillars and GSLs}

In response to wounding treatment, total, aliphatic, or indolic GSL levels remained unaffected (Figs. 6A, 7I, M, P, and S, and $8 \mathrm{G}$ and I). We did not observe any change in the transcript expression of aliphatic AtMYB-related transcription factors (Fig. 7A, D, and G); Gigolashvili et al. (2007b) observed a rapid AtMYB28 induction in the first 5 min after wounding, but expression quickly returned to basal levels. Even though there was a slight increase in AtMYB34 levels, foliar indolic GSL levels remained unchanged (Fig. 8A). Our observations support previous reports in which wounding (pinching leaves with ribbed forceps) did not affect foliar aliphatic GSL levels and only had minor effects on indolic GSLs that were noted after $48 \mathrm{~h}$ (Mikkelsen et al. 2003). In contrast, wounding increased AtMYB transcription factor expression in a study by Paudel et al. (2016); it is noteworthy that the rate of nitrogen fertilizer affected transcriptional patterns, with AtMYB28 and AtMYB29 being wound induced in plants that had lower nitrate fertilization levels, and AtMYB51 levels increased in damaged plants with higher fertilization rates. This translated into higher levels of the aliphatic GSL glucoalyssin (ALY) in wounded plants fertilized by lower nitrate rates. Indolic GSL levels were higher in wounded plants, irrespective of nitrogen fertilizer levels, which mainly reflected GBC levels. In comparison, in the related plant Brassica nigra, nitrogen fertilization corresponded to higher indolic GSLs in wounded plants with little effect on aliphatic GSLs (Landosky and Karowe 2014).

The majority of arabidopsis foliar GSLs are methioninederived aliphatic compounds whose biosynthesis is regulated through AtMYB28, AtMYB29, and AtMYB76 transcription factors (Gigolashvili et al. 2008; Li et al. 2013; Mewis et al. 2005); in particular, AtMYB28 is involved in the regulation of short-chain aliphatic GSLs. Aliphatic GSLs are induced by jasmonates in a MYC2/3/4-, COI1-dependent fashion and enhanced by the ethylene pathway (Frerigmann and Gigolashvili 2014; Hirai et al. 2007; Mewis et al. 2005; Schweizer et al. 2013). MYC2/3/4 transcription factors bind to the promoter regions of genes encoding enzymes in GSL biosynthesis and physically interact with AtMYB28 and AtMYB34 to regulate GSL biosynthesis (Schweizer et al. 2013). In contrast, SA/NPR1 and gibberellin pathways negatively regulate aliphatic GSL biosynthesis (Mewis et al. 2006; Schweizer et al. 2013). Foliar AtMYB28 expression is induced in response to $T$. $n i$ and $S$. exigua caterpillar herbivory (Fig. 7B and C); in particular, strong induction is observed at $12 \mathrm{~h}$ in response to $S$. exigua herbivory, and it drops over the next $24 \mathrm{~h}$. This is mirrored in levels of the shortchain aliphatic GSL ERU (4-methylthiobutyl GSL) in response to $S$. exigua caterpillar attack, but not $T$. $n i$ (Fig. $7 \mathrm{~N}$ and O). Other studies have found that $S$. exigua herbivory induced ERU levels as well as the biosynthetically related compound RAPH (4methylsulfinylbutyl GSL) (Mewis et al. 2005, 2006). In that, as well as our study, an increase in the long-chain aliphatic GSL HIR (8-methylsulfinyloctyl GSL) level is also observed in $S$. exigua-infested plants (Fig. 7U). Similarly, total aliphatic levels are not changed by herbivory by another generalist caterpillar, $M$. brassicae, but there is an increase in RAPH and concomitant decrease in its precursor ERU as well as an increase in ALY (5methylsulfinylpentyl GSL) (Pangesti et al. 2016). Therefore, a number of studies have shown that there may be fluctuations in the type of aliphatic GSL, but in general total aliphatic GSL levels are not induced by generalist caterpillars (Badenes-Perez et al. 2013; Kos et al. 2012; Pangesti et al. 2016). In comparison, aliphatic GSL levels increase in arabidopsis damaged by specialist caterpillars, such as $P$. rapae (Kos et al. 2012; Verhage et al. 2011); however, there are exceptions, because other studies have found no change or lower foliar aliphatic GSL levels after herbivory by specialist $P$. rapae or $P$. xylostella caterpillars (Badenes-Perez et al. 2013; Mewis et al. 2006). Lee et al. (2018) determined that $P$. xylostella herbivory induced glucoiberin (IBE) and suppressed sinigrin, ERU, and the indole GSL GBC through a brassinosteroid-mediated pathway (Guo et al. 2013).

AtMYB34 and AtMYB51 transcription factors are the main regulators of indole GSL biosynthesis-related gene expression responsible for root and shoot biosynthesis, respectively, with AtMYB122 playing a minor role (Frerigmann and Gigolashvili 2014). Induction of indole GSLs are jasmonate COI1-, MYC2dependent, and induction of total indole GSLs are suppressed by the ethylene (via ORA59), ABA, gibberellin, and SA/NPR1 pathways (Frerigmann and Gigolashvili 2014; Mewis et al. 2006; Mikkelsen et al. 2003; Pangesti et al. 2016; Schweizer et al. 2013; Stotz et al. 2000). SA or ethylene treatment increases levels of 4-methoxyindoyl-3-yl (4MeOGBC). AtMYB34 and AtMYB51 are also brassinosteroid-responsive (Sun et al. 2010). Although AtMYB34 expression was induced in response to all treatments (Fig. 8A to C), the indolic GSL GBC is only elevated in leaf tissue from S. exigua-attacked plants (Fig. 8G to I). This may reflect root GSL induction and transport to the shoot or, 
alternatively, AtMYB51 may have contributed to induction of GSL biosynthesis genes, but the peak of AtMYB51 expression, approximately $3 \mathrm{~h}$ after wounding (Frerigmann et al. 2015), may not have been captured in the timepoints of this experiment. Other studies have also observed an increase in indolic GSL, primarily GBC and/or 4MeOGBC, levels in response to caterpillar herbivory (Lan et al. 2014; Pangesti et al. 2016), with some exceptions such a study with $P$. rapae (Mewis et al. 2006). Herbivory by $P$. xylostella caterpillars changed the indolic GSL profile, decreasing the biosynthetically related GBC and 4MeOGBC content with a concomitant increase in neoglucobrassicin (neoGBC), without affecting total levels (Badenes-Perez et al. 2013).
The observed variability in GSL profile may reflect crosstalk between phytohormone signaling networks that shape the GSL biosynthesis that is, in part, mediated by effectors from the caterpillar (Acevedo et al. 2015; Ballaré 2011; Basu et al. 2018; Caarls et al. 2015; Howe et al. 2018). Mewis et al. (2006) identified COI1-dependent attenuation of aliphatic and induction of indolic GSL accumulation, NPR1-mediated attenuation of both aliphatic and indolic GSL accumulation, and ethylene only suppressed indolic GSL accumulation. P. rapae caterpillars activate COI1-dependent suppression of aliphatic GSL induction and the NPR1- as well as ethylene-dependent inhibition of indole GSL accumulation, to maintain low GSL levels (Mewis et al.

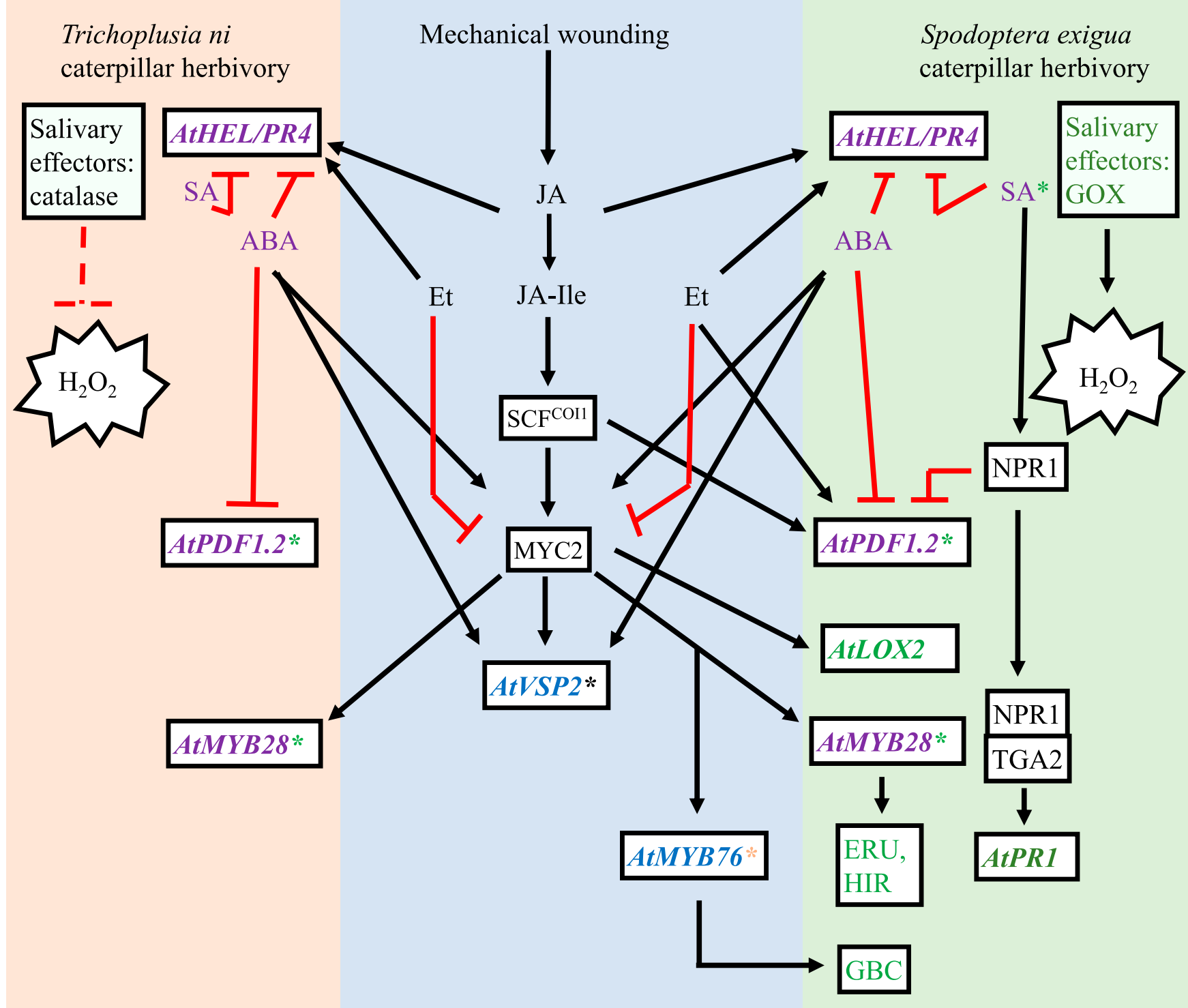

FIGURE 9

Proposed model of plant responses to wounding and herbivory by two generalist caterpillar species, Trichoplusia ni or Spodoptera exigua. Because caterpillars damage the plants as they feed, there is significant overlap between these treatments; mechanical wounding (blue panel) and herbivory by T. ni (orange panel) and S. exigua (green panel) caterpillars. Distinctions between plant responses to mechanical damage or caterpillar herbivory likely reflect recognition of effectors in caterpillar oral secretions. Color coding denotes the plant responses with orange indicating responses to $T$. ni herbivory, green indicating responses to $S$. exigua herbivory, purple indicating response to caterpillar herbivory, and blue indicating changes to any of the three treatments. An asterisk denotes when a time-dependent response was noted and is, again, color coded. Ethylene (Et) was not measured in these experiments. Dashed lines represent putative pathways. Abbreviations for the phytohormones: ABA = abscisic acid; JA = jasmonic acid; JA-lle = 7-iso-jasmonyl-L-isoleucine; OPDA = 12-oxophytodienoic acid; SA = salicylic acid. Abbreviations for the glucosinolates: GBC = glucobrassicin; ERU (4-methylthiobutyl GSL) = glucoerucin; and HIR (8-methylsulfinyloctyl GSL) = glucohirsutin. $\mathrm{H}_{2} \mathrm{O}_{2}$ = hydrogen peroxide; GOX = glucose oxidase. 
2006); in contrast, S. exigua herbivory activates a COI1-dependent accumulation of indolic GSLs. The activation of the jasmonate pathway that induces indole GSL accumulation in response to $S$. exigua herbivory is dependent on negative growth regulator DELLA proteins (Lan et al. 2014).

\section{CONCLUSIONS}

Wounding, either mechanical or through caterpillar herbivory, activates the jasmonate pathway that can be modified by caterpillarmediated stimulation of other phytohormone pathways to effect induced responses (Fig. 9). Caterpillar HAMPs reflect, at least in part, effectors in their oral secretions, such as the regurgitant and labial saliva. Perhaps the best characterized labial salivary effector is the enzyme GOX (Bede et al. 2006; Musser et al. 2002). Through the oxidation of glucose, GOX catalyzes the production of $\mathrm{H}_{2} \mathrm{O}_{2}$, an important player in the regulation of a number of phytohormone pathways, notably the ethylene and SA/NPR1 pathways (Černý et al. 2018; Chamnongpol et al. 1998; Desikan et al. 2005; León et al. 1995; Mhamdi et al. 2010; Mittler et al. 2011; Vanderauwera et al. 2005). Even though this enzyme, which is present in S. exigua labial salivary glands and oral secretions (Afshar et al. 2010, 2013; Diezel et al. 2009; Eichenseer et al. 2010), has been reported in T. ni salivary glands, its presence was not observed in recent saliva proteomic studies (Eichenseer et al. 2010; Rivera-Vega et al. 2018). Instead, catalase, an enzyme that decomposes $\mathrm{H}_{2} \mathrm{O}_{2}$, has been identified in T. $n i$ saliva (Rivera-Vega et al. 2018). Therefore, in the caterpillar labial saliva, $S$. exigua has an enzyme (GOX) that promotes $\mathrm{H}_{2} \mathrm{O}_{2}$ production, and $T$. $n i$ has an enzyme (catalase) that breaks down $\mathrm{H}_{2} \mathrm{O}_{2}$ (Eichenseer et al. 2010; Rivera-Vega et al. 2018). Arabidopsis foliar expression of AtPRl and AtPDF1.2 differ between attack by these two caterpillar species. AtPRI expression, only observed in response to $S$. exigua herbivory, indicates activation of the SA/NPR1-dependent pathway. Previously, it has been shown that $S$. exigua SA/NPR1-, TGA2/5/6-dependent AtPRl expression is caterpillar labial saliva-dependent (Paudel and Bede 2015; Paudel et al. 2013). As well, S. exigua but not T. $n i$ herbivory increased indolic GSL, particularly GBC, levels (Figs. 6B and C, $8 \mathrm{H}$ and I). Sewelam et al. (2014) identified a connection between peroxisomal-generated $\mathrm{H}_{2} \mathrm{O}_{2}$ and indolic GSL biosynthesis, primarily mediated through AtMYB51. Therefore, it is possible that effectors in the caterpillar saliva that affect cellular $\mathrm{H}_{2} \mathrm{O}_{2}$ levels may modulate plant defense responses affecting indolic GSL biosynthesis and activating the SA/NPR1 pathway to antagonize AtPDF1.2 expression. Studies are continuing to further understand the regulation of plant defense responses by caterpillar salivary effectors that contribute to these unique profiles.

\section{ACKNOWLEDGMENTS}

We thank Dongeun Go and Ruoxi Liu for assisting with experiments and Diljot Kaur for critical reading of this manuscript. We thank the anonymous reviewers for their suggestions to improve this article. Authors' contributions: Experimental design was conceived of by $\mathrm{ZZ}$ and JCB and conducted by ZZ under the supervision of JCB. Glucosinolate and phytohormone analysis was conducted by RS and AS, under the supervision of NMvD. Instrumentation and technical expertise were provided by BTD. Gene expression analysis was performed by ZZ under the supervision of JCB. Data were analyzed and manuscript was written by $\mathrm{ZZ}$ and JCB, with valuable input from BTD, RS, AS, and NMvD.

\section{LITERATURE CITED}

Abe, H., Urao, T., Ito, T., Seki, M., Shinozaki, K., and Yamaguchi-Shinozaki, K. 2003. Arabidopsis AtMYC2 (bHLH) and AtMYB2 (MYB) function as transcriptional activators in abscisic acid signaling. Plant Cell 15:63-78.
Acevedo, F. E., Rivera-Vega, L. J., Chung, S. H., and Felton, G. W. 2015. Cues from chewing insects - The intersection of DAMPs, HAMPs, MAMPs and effectors. Curr. Opin. Plant Biol. 26:80-86.

Afshar, K., Dube, F. F., Najafabad, H. S., Bonneil, É., Thibault, P., Salivati, R., and Bede, J. C. 2013. Insights into the insect salivary gland proteome: Diet-associated changes in caterpillar labial salivary proteins. J. Insect Physiol. 59:351-366.

Afshar, K., Dufresne, P. J., Pan, L., Merkx-Jacques, M., and Bede, J. C. 2010. Diet-specific salivary gene expression and glucose oxidase activity in Spodoptera exigua (Lepidoptera: Noctuidae) larvae. J. Insect Physiol. 56: 1798-1806.

Anderson, J. P., Badruzsaufari, E., Schenk, P. M., Manners, J. M., Desmond, O. J., Ehlert, C., Maclean, D. J., Ebert, P. R., and Kazan, K. 2004. Antagonistic interaction between abscisic acid and jasmonate-ethylene signaling pathways modulates defense gene expression and disease resistance in Arabidopsis. Plant Cell 16:3460-3479.

Andersen, T. G., Nour-Eldin, H. H., Fuller, V. L., Olsen, C. E., Burow, M., and Halkier, B. A. 2013. Integration of biosynthesis and long-distance transport establish organ-specific glucosinolate profiles in vegetative Arabidopsis. Plant Cell 25:3133-3145.

Appel, H. M., Fescemyer, H., Ehlting, J., Weston, D., Rehrig, E., Joshi, T., Xu, D., Bohlmann, J., and Schultz, J. 2014. Transcriptional responses of Arabidopsis thaliana to chewing and sucking insect herbivores. Front. Plant Sci. 5:565.

Aranda, P. S., LaJoie, D. M., and Jorcyk, C. L. 2012. Bleach gel: A simple agarose gel for analyzing RNA quality. Electrophoresis 33:366-369.

Arnold, M. D., Gruber, C., Floková, K., Miersch, O., Strnad, M., Novák, O., Wasternack, C., and Hause, C. 2016. The recently identified isoleucine conjugate of cis-12-oxo-phytodienoic acid is partially active in cis-12-oxophytodienoic acid-specific gene expression of Arabidopsis thaliana. PLoS One 11:e0162829.

Badenes-Perez, F. R., Reichelt, M., Gershenzon, J., and Heckel, D. G. 2013. Interaction of glucosinolate content of Arabidopsis thaliana mutant lines and feeding and oviposition by generalist and specialist lepidopterans. Phytochemistry 86:36-43.

Ballaré, C. 2011. Jasmonate-induced defenses: A tale of intelligence, collaborators and rascals. Trends Plant Sci. 16:249-257.

Basu, S., Varsani, S., and Louis, J. 2018. Altering plant defenses: Herbivoreassociated molecular patterns and effector arsenal of chewing herbivores. Mol. Plant-Microbe Interact. 31:13-21.

Beckers, G. J. M., and Spoel, S. H. 2006. Fine-tuning plant defence signalling: Salicylate versus jasmonate. Plant Biol. 8:1-10.

Bede, J. C., Musser, R. O., Felton, G. W., and Korth, K. L. 2006. Caterpillar herbivory and salivary enzymes decrease transcript levels of Medicago truncatula genes encoding early enzymes in terpenoid biosynthesis. Plant Mol. Biol. 60:519-531.

Beekwilder, J. van Leeuwen, W., van Dam, N. M., Bertossi, M., Grandi, V., Mizzi, L., Soloviev, M., Szabados, L., Molthoff, J. W., Schipper, B., Verbocht, H., de Vos, R. C. H., Morandini, P., Aarts, M. G. M., and Bovy, A. 2008. The impact of the absence of aliphatic glucosinolates on insect herbivory in Arabidopsis. PLoS One 3:e2068.

Bell, E., Creelman, R. A., and Mullet, J. E. 1995. A chloroplast lipoxygenase is required for wound-induced jasmonic acid accumulation in Arabidopsis. Proc. Natl. Acad. Sci. U.S.A. 92:8675-8679.

Blanco, F., Garretón, V., Frey, N., Dominguez, C., Pérez-Acle, T., Van der Straeten, D., Jordana, X., and Holuigue, L. 2005. Identification of NPR1dependent and independent genes early induced by salicylic acid treatment in Arabidopsis. Plant Mol. Biol. 59:927-944.

Bodenhausen, N., and Reymond, P. 2007. Signaling pathways controlling induced resistance to insect herbivores in Arabidopsis. Mol. Plant-Microbe Interact. 20:1406-1420.

Bown, A. W., Hall, D. E., and MacGregor, K. B. 2002. Insect footsteps on leaves stimulate the accumulation of 4-aminobutyrate and can be visualized through increased chlorophyll fluorescence and superoxide production. Physiol. Plant 129:1430-1434.

Boyes, D. C., Zayed, A. M., Ascenzi, R., McCaskill, A. J., Hoffman, N. E., Davis, K. R., Görlach, J. 2001. Growth stage-based phenotypic analysis of Arabidopsis: A model for high throughput functional genomics in plants. Plant Cell 13:1499-1510.

Broekgaarden, C., Caarls, L., Vos, I. A., Pieterse, C. M. J., and Van Wees, S. C. M. 2015. Ethylene: Traffic controller on hormonal crossroads to defense. Plant Physiol. 169:2371-2379.

Brown, P. D., Tokuhisa, J. G., Reichelt, M., and Gershenzon, J. 2003. Variation of glucosinolate accumulation among different organs and developmental stages of Arabidopsis thaliana. Phytochemistry 62: 471-481.

Burow, M., and Halkier, B. A. 2017. How does a plant orchestrate defense in time and space? Using glucosinolates in Arabidopsis as a case study. Curr. Opin. Plant Biol. 38:142-147. 
Caarls, L., Pieterse, C. M. J., and van Wees, S. C. M. 2015. How salicylic acid takes transcriptional control over jasmonic acid signaling. Front. Plant Sci. 6:170.

Černý, M., Habánová, H., Berka, M., Luklová, M., and Brzobohatý, B. 2018. Hydrogen peroxide: Its role in plant biology and crosstalk with signalling networks. Int. J. Mol. Sci. 19:2812.

Chamnongpol, S., Willekens, H., Moeder, W., Langbartels, C., Sandermann Jr., H., Van Montagu, M., Inzé, D., and Van Camp, W. 1998. Defense activation and enhanced pathogen tolerance induced by $\mathrm{H}_{2} \mathrm{O}_{2}$ in transgenic tobacco. Proc. Natl. Acad. Sci. U.S.A. 95:5818-5823.

Chen, H.-Y., Hsieh, E.-J., Cheng, M.-C., Chen, C.-Y., Hwang, S.-Y., and Lin, T.-P. 2016. ORA47 (octadecanoid-responsive AP2/ERF-domain transcription factor 47) regulates jasmonic acid and abscisic acid biosynthesis and signaling through binding to a novel cis-element. New Phytol. 211:599-613.

Chini, A., Fonseca, S., Fernández, G., Adie, B., Chico, J. M., Lorenzo, O., García-Casado, G., López-Vidriero, I., Lozano, F. M., Ponce, M. R., Micol, J. L., and Solano, R. 2007. The JAZ family of repressors is the missing link in jasmonate signalling. Nature 448:666-671.

Danner, H., Desurmont, G. A., Cristescu, S. M., and van Dam, N. M. 2018. Herbivore-induced plant volatiles accurately predict history of coexistence, diet breadth, and feeding mode of herbivores. New Phytol. 220:726-738.

Desikan, R., Hancock, J. T., Bright, J., Harrison, J., Weir, I., Hooley, R., and Neill, S. J. 2005. A role for ETR1 in hydrogen peroxide signaling in stomatal guard cells. Plant Physiol. 137:831-834.

Després, C., Chubak, C., Rochon, A., Clark, R., Bethune, T., Desveaux, D., and Fobert, P. R. 2003. The Arabidopsis NPR1 disease resistance protein is a novel cofactor that confers redox regulation of DNA binding activity to the basic domain/leucine zipper transcription factor TGA1. Plant Cell 15: 2181-2191.

Diezel, C., von Dahl, C. C., Gaquerel, E., and Baldwin, I. T. 2009. Different lepidopteran elicitors account for cross-talk in herbivory-induced phytohormone signaling. Plant Physiol. 150:1576-1586.

Dombrecht, B., Xue, G. P., Sprague, S. J., Kirkegaard, J. A., Ross, J. J., Reid, J. B., Fitt, G. P., Sewelam, N., Schenk, P. M., Manners, J. M., and Kazan, K. 2007. MYC2 differentially modulates diverse jasmonate- dependent functions in Arabidopsis. Plant Cell 19:2225-2245.

Ebling, P. M., and Dedes, J. 2015. Rearing Trichoplusia ni. Insect Production Services Standard Operating Procedure. https://cfs.nrcan.gc.ca/ publications? id=36012.

Eichenseer, H., Mathews, M. C., Powell, J. S., and Felton, G. W. 2010. Survey of a salivary effector in caterpillars: Glucose oxidase variation and correlation with host range. J. Chem. Ecol. 36:885-897.

Erb, M., and Reymond, P. 2019. Molecular interactions between plants and insect herbivores. Annu. Rev. Plant Biol. 70:527-557.

Frerigmann, H., and Gigolashvili, T. 2014. MYB34, MYB51, and MYB122 distinctly regulate indolic glucosinolate biosynthesis in Arabidopsis thaliana. Mol. Plant 7:814-828.

Frerigmann, H., Glawischnig, E., and Gigolashvili, T. 2015. The role of MYB34, MYB51 and MYB122 in the regulation of camalexin biosynthesis in Arabidopsis thaliana. Front. Plant Sci. 6:654.

Gigolashvili, T., Berger, B., Mock, H., Müller, C., Weisshaar, B., and Flügge, U. 2007b. The transcription factor HIG1/MYB51 regulates indolic glucosinolate biosynthesis in Arabidopsis thaliana. Plant J. 50:886-901.

Gigolashvili, T., Engqvist, M., Yatusevich, R., Müller, C., and Flügge, U. 2008. HAG2/MYB76 and HAG3/MYB29 exert a specific and coordinated control on the regulation of aliphatic glucosinolate biosynthesis in Arabidopsis thaliana. New Phytol. 177:627-642.

Gigolashvili, T., Yatusevich, R., Berger, B., Müller, C., and Flügge, U. I. 2007a. The R2R3-MYB transcription factor HAG1/MYB28 is a regulator of methionine-derived glucosinolate biosynthesis in Arabidopsis thaliana. Plant J. 51:247-261.

Grosser, K., and van Dam, N. M. 2017. A straightforward method for glucosinolate extraction and analysis with high-pressure liquid chromatography (HPLC). J. Vis. Exp. 121:55425.

Guo, R., Shen, W., Qian, H., Zhang, M., Liu, L., and Wang, Q. 2013. Jasmonic acid and glucose synergistically modulate the accumulation of glucosinolates in Arabidopsis thaliana. J. Exp. Bot. 64:5707-5719.

Halkier, B. A., and Gershenzon, J. 2006. Biology and biochemistry of glucosinolates. Annu. Rev. Plant Biol. 57:303-333.

Han, Y., Mhamdi, A., Chaouch, S., and Noctor, G. 2013. Regulation of basal and oxidative stress-triggered jasmonic acid-related gene expression by glutathione. Plant Cell Environ. 36:1135-1146.

Hanschen, F. S., Pfitzmann, M., Witzel., K, Stützel, H., Schreiner, M., and Zrenner, R. 2018. Differences in the enzymatic hydrolysis of glucosinolates increase the defense metabolite diversity in 19 Arabidopsis thaliana accessions. Plant Physiol. Biochem. 124:126-135.

He, X., Jiang, J., Wang, C.-Q., and Dehesh, K. 2017. ORA59 and EIN3 interaction couples jasmonate-ethylene synergistic action to antagonistic salicylic acid regulation of PDF expression. J. Integrative Plant Biol. 59:275-287.
Heidel-Fischer, H. M., Kirsch, R., Reichelt, M., Ahn, S.-J., Wielsch, N., Baxter, S. W., Heckel, D. G., Vogel, H., and Kroymann, J. 2019. An insect counteradaptation against host plant defenses evolved through concerted neofunctionalization. Mol. Biol. Evol. 36:930-941.

Herrera-Vásquez, A., Carvallo, L., Blanco, F., Tobar, M., Villarreol-Candia, E., Vincente-Carbojosa, J., Salinas, P., and Holuigue, L. 2015. Transcriptional control of glutaredoxin GRXC9 expression by a salicylic aciddependent and NPR1-independent pathway in Arabidopsis. Plant Mol. Biol. Rep. 33:624-637.

Hettenhausen, C., Schuman, M. C., and Wu, J. 2015. MAPK signaling - A key element in plant defense response to insects. Insect Sci. 22:157-164.

Hirai, M. Y., Sugiyama, K., Sawada, Y., Tohge, T., Obayashi, T., Suzuki, A., Araki, R., Sakurai, N., Suzuki, H., Aoki, K., Goda, H., Nishizawa, O. I., Shibata, D., and Saito, K. 2007. Omics-based identification of Arabidopsis Myb transcription factors regulating aliphatic glucosinolate biosynthesis. Proc. Natl. Acad. Sci. U.S.A. 104:6478-6483.

Hopkins, R. J., van Dam, N. M., and van Loon, J. J. A. 2009. Role of glucosinolates in insect-plant relationships and multitrophic interactions. Ann. Rev. Entomol. 54:57-83.

Howard, R. J., Garland, J. A., Seaman, W. L., and Grafius, E. J. 1996 Diseases and pests of vegetable crops in Canada. J. Econ. Entomol. 89: 1045-1046.

Howe, G. A., and Jander, G. 2008. Plant immunity to insect herbivores. Annu. Rev. Plant Biol. 59:41-66.

Howe, G. A., Major, I. T., and Koo, A. J. 2018. Modularity in jasmonate signaling for multistress resistance. Annu. Rev. Plant Biol. 69: 387-415.

Hunziker, P., Halkier, B. A., and Schulz, A. 2019. Arabidopsis glucosinolate storage cells transform into phloem fibers at late stages of development. J. Exp. Bot. 70:4305-4317.

Jeschke, V., Gershenzon, J., and Vassão, D. G. 2016. Insect detoxification of glucosinolates and their hydrolysis products. Adv. Bot. Res. 80:199-245.

Jeschke, V., Kearney, E. E., Schramm, K., Kunert, G., Shekhov, A., Gershenzon, J., and Vassão, D. G. 2017. How glucosinolates affect generalist lepidopteran larvae: Growth, development and glucosinolate metabolism. Front. Plant Sci. 8:1995.

Kimura, K., and Tsubaki, Y. 1986. Female size and age-specific fecundity in the small white butterfly, Pieris rapae crucivora Boisduval (Lepidoptera: Pieridae). Res. Pop. Ecol. 28:295-304.

Kliebenstein, D., Pedersen, D., Barker, B., and Mitchell-Olds, T. 2002. Comparative analysis of quantitative trait loci controlling glucosinolates, myrosinase and insect resistance in Arabidopsis thaliana. Genetics 161:325-332.

Kliebenstein, D. J., Kroymann, J., Brown, P., Figuth, A., Pedersen, D., Gershenzon, J., and Mitchell-Olds, T. 2001. Genetic control of natural variation in Arabidopsis glucosinolate accumulation. Plant Physiol. 126:811-825.

Koornneef, A., Leon-Reyes, A., Ritsema, T., Verhage, A., Den Otter, F. C., Van Loon, L. C., and Pieterse, C. M. J. 2008. Kinetics of salicylatemediated suppression of jasmonate signaling reveal a role for redox modulation. Plant Physiol. 147:1358-1368.

Koroleva, O. A., and Cramer, R. 2011. Single-cell proteomic analysis of glucosinolate-rich S-cells in Arabidopsis thaliana. Methods 54:413-423.

Koroleva, O. A., Gibson, T. M., Cramer, R., and Stain, C. 2010 Glucosinolate-accumulating S-cells in Arabidopsis leaves and flower stalks undergo programmed cell death at early stages of differentiation. Plant J. 64:456-469.

Kos, M., Houshyani, B., Wietsma, R., Kabouw, P., Vet, L. E. M., van Loon, J. J. A., and Dicke, M. 2012. Effects of glucosinolates on a generalist and specialist leaf-chewing herbivore and an associated parasitoid. Phytochemistry 77:162-170.

La Camera, S., L'Haridon, F., Astier, J., Zander, M., Abou-Mansour, E., Page, G., Thurow, C., Wendehenne, D., Gatz, C., Métraux, J.-P., and Lamotte, O. 2011. The glutaredoxin ATGRXS13 is required to facilitate Botrytis cinerea infection of Arabidopsis thaliana plants. Plant J. 68:507-519.

Lambrix, V., Reichelt, M., Mitchell-Olds, T., Kliebenstein, D. J., and Gershenzon, J. 2001. The Arabidopsis epithiospecifier protein promotes the hydrolysis of glucosinolates to nitriles and influences Trichoplusia $n i$ herbivory. Plant Cell 13:2793-2807.

Lan, Z., Krosse, S., Achard, P., van Dam, N. M., and Bede, J. C. 2014. DELLA proteins modulate Arabidopsis defences induced in response to caterpillar herbivory. J. Exp. Bot. 65:571-583.

Landosky, J. M., and Karowe, D. N. 2014. Will chemical defenses become more effective against specialist herbivores under elevated $\mathrm{CO}_{2}$ ? Global Change Biol. 20:3159-3176.

Lee, J. H., Lee, J., Kim, H., Chae, W. B., Kim, S.-J., Lee, J. H., Lim, Y. P., and Oh, M.-H. 2018. Brassinosteroids regulate glucosinolate biosynthesis in Arabidopsis thaliana. Physiol. Plant. 163:450-458.

León, J., Lawton, M. A., and Raskin, I. 1995. Hydrogen peroxide stimulates salicylic acid biosynthesis in tobacco. Plant Physiol. 108: 1673-1678. 
Leon-Reyes, A., Du, Y., Koorneef, A., Proietti, S., Körbes, A. P., Memelink J., Pieterse, C. M. J., and Ritsema, T. 2010a. Ethylene signaling renders the jasmonate response of Arabidopsis insensitive to future suppression by salicylic acid. Mol. Plant-Microbe Interact. 23:187-197.

Leon-Reyes, A., Spoel, S. H., De Lange, E. S., Abe, H., Kobayashi, M., Tsuda, S., Millenaar, F. F., Welschen, R. A. M., Ritsema, T., and Pieterse, C. M. J. 2009. Ethylene modulates the role of NONEXPRESSOR OF PATHOGENESIS-RELATED GENES1 in cross talk between salicylate and jasmonate signaling. Plant Physiol. 149:1797-1809.

Leon-Reyes, A., Van der Does, D., De Lange, E. S., Delker, C., Wasternack, C., Van Wees, S. C. M, Ritsema, T., and Pieterse, C. M. J. 2010 b. Salicylate-mediated suppression of jasmonate-responsive gene expression in Arabidopsis is targeted downstream of the jasmonate biosynthesis pathway. Planta 232:1423-1432.

Li, B., Tang, M., Nelson, A., Caligagan, H., Zhou, X., Clark-Wiest, C., Ngo, R., Brady, S. M., and Kliebenstein, D. J. 2018. Network-guided discovery of extensive epistasis between transcription factors involved in aliphatic glucosinolate biosynthesis. Plant Cell 30:178-195.

Li, N., Han, X., Feng, D., Yuan, D., and Huang, L.-J. 2019. Signaling crosstalk between salicylic acid and ethylene/jasmonate in plant defense: Do we understand what they are whispering. Int. J. Mol. Sci. 20: 671.

Li, Q., Eigenbrode, S. D., Stringam, G. R., and Thiagarajah, M. R. 2000. Feeding and growth of Plutella xylostella and Spodoptera eridania on Brassica juncea with varying glucosinolate concentrations and myrosinase activities. J. Chem. Ecol. 26:2401-2419.

Li, Y., Sawada, Y., Hirai, A., Sato, M., Kuwahara, A., Yan, X., and Hirai, M. Y. 2013. Novel insights into the function of Arabidopsis R2R3-MYB transcription factors regulating aliphatic glucosinolate biosynthesis. Plant Cell Physiol. 54:1335-1344.

Lindermayr, C., Sell, S., Muller, B., Leister, D., and Durner, J. 2010. Redox regulation of the NPR1-TGA1 system of Arabidopsis thaliana by nitric oxide. Plant Cell 22:2894-2907.

Lorenzo, O., Chico, J. M., Sánchez-Serrano, J. J., and Solano, R. 2004. JASMONATE-INSENSITIVE1 encodes a MYC transcription factor essential to discriminate between different jasmonate-regulated defense responses in Arabidopsis. Plant Cell 16:1938-1950.

Louis, J., Luthe, D. S., and Felton, G. W. 2013. Salivary signals of European corn borer induce indirect defenses in tomato. Plant Signal. Behav. 8: e27318.

Madsen, S. R., Olsen, C. E., Nour-Eldin, H. H., and Halkier, B. A. 2014. Elucidating the role of transport processes in leaf glucosinolate distribution. Plant Physiol. 166:1450-1462.

Martinez Henao, J., Demers, E. L., Grosser, K., Schedl, A., van Dam, N. M., and Bede J. C. 2020. Fertilizer rate-associated increase in foliar jasmonate burst observed in wounded Arabidopsis thaliana leaves is attenuated at $\mathrm{eCO}_{2}$. Front. Plant Sci. 10:1636.

Mewis, I., Appel, H. M., Hom, A., Raina, R., and Schultz, J. C. 2005. Major signaling pathways modulate Arabidopsis glucosinolate accumulation and response to both phloem-feeding and chewing insects. Plant Physiol. 138: $1149-1162$.

Mewis, I., Tokuhisa, J. G., Schultz, J. C., Appel, H. M., Ulrichs, C., and Gershenzon, J. 2006. Gene expression and glucosinolate accumulation in Arabidopsis thaliana in response to generalist and specialist herbivores of different feeding guilds and the role of defense signaling pathways. Phytochemistry 67:2450-2462.

Mhamdi, A., Hager, J., Chaouch, S., Queval, G., Han, Y., Taconnat, L., Saindrenan, P., Gouia, H., Issakidis-Bourguet, E., Renou, J.-P., and Noctor, G. 2010. Arabidopsis GLUTATHIONE REDUCTASE1 plays a crucial role in leaf responses to intracellular hydrogen peroxide and in ensuring appropriate gene expression through both salicylic acid and jasmonic acid signaling pathways. Plant Physiol. 153:1144-1160.

Mikkelsen, M. D., Petersen, B. L., Glawischnig, E., Jensen, A. B., Andreasson, E., and Halkier, B. A. 2003. Modulation of CYP79 genes and glucosinolate profiles in Arabidopsis by defense signaling pathways. Plant Physiol. 131:298-308.

Mittler, R., Kim, Y. S., Song, L., Coutu, J., Coutu, A., Ciftci-Yilmaz, S., Lee, H., Stevenson, B., and Zhu, J.-K. 2006. Gain- and loss-of-function mutations in Zat10 enhance the tolerance of plants to abiotic stress. FEBS Lett. 580:6537-6542.

Mittler, R., Vanderauwera, S., Suzuki, N., Miller, G., Bognetti, V. B., Vandepoele, K., Gollery, M., Shulaev, V., and Van Breusegem, F. 2011. ROS signaling: The new wave? Trends Plant Sci. 16:300-309.

Mosleh Arany, A., de Jong, T. J., Kim, H. K., van Dam, N. M., Choi, Y. H., Verpoorte, R., and van der Meijden, E. 2008. Glucosinolates and other metabolites in the leaves of Arabidopsis thaliana from natural populations and their effects on a generalist and a specialist herbivore. Chemoecology 18:65-71
Mou, Z., Fan, W., and Dong, X. 2003. Inducers of plant systemic acquired resistance regulate NPR1 function through redox changes. Cell 113: 935-944.

Mouradov, A., Cremer, F., and Coupland, G. 2002. Control of flowering time: Interacting pathways as a basis of diversity. Plant Cell 14:S111-S130.

Müller, R., de Vos, M., Sun, J. Y., Sønderby, I. E., Halkier, B. A., Wittstock, U., and Jander, G. 2010. Differential effects of indole and aliphatic glucosinolates on lepidopteran herbivores. J. Chem. Ecol. 36:905-913.

Mur, L. A. J., Naylor, G., Warner, S. A. J., Sugars, J. M., White, R. R., and Draper, J. 1996. Salicylic acid potentiates defence gene expression in tissue exhibiting acquired resistance to pathogen attack. Plant J. 9:559-571.

Musser, R. O., Hum-Musser, S. M., Eichenseer, H., Peiffer, M., Ervin, G., Murphy, J. B., and Felton, G. W. 2002. Caterpillar saliva beats plant defenses. Nature 416:599-600.

Nakata, M., Mitsuda, N., Herde, M., Koo, A. J., Moreno, J. E., Suzuki, K., Howe, G. A., and Ohme-Takagi, M. 2013. A bHLH-type transcription factor, ABA-INDUCIBLE BHLH-TYPE TRANSCRIPTION FACTOR/ JA-ASSOCIATED MYC2-LIKE1, acts as a repressor to negatively regulate jasmonate signaling in Arabidopsis. Plant Cell 25:1641-1656.

Ndamukong, I., Abdallat, A. A., Thurow, C., Fode, B., Zander, M., Weigel, R., and Gatz, C. 2007. SA-inducible Arabidopsis glutaredoxin interacts with TGA factors and suppresses JA-responsive PDF1.2 transcription. Plant J. 50:128-139.

Nintemann, S. J., Hunziker, P., Andersen T. G., Schulz, A., Burow, M., and Halkier, B. A. 2018. Localization of glucosinolate biosynthetic enzymes reveals distinct spatial patterns for the biosynthesis of indole and aliphatic glucosinolates. Physiol. Plant. 163:138-154.

O’Donnell, P. J., Calvert, C., Atzorn, R., Wasternack, C., Leyser, H. M. O., and Bowles, D. J. 1996. Ethylene as a signal mediating the wound response of tomato plants. Science 274:1914-1917.

Pangesti, N., Reichelt, M., van de Mortel, J. E., Kapsomenou, E., Gershenzon, J., van Loon, J. J. A., Dicke, M., and Pineda, A. 2016. Jasmonic acid and ethylene signaling regulate glucosinolate levels in plants during rhizobacteria-induced systemic resistance against a leaf-chewing herbivore. J Chem. Ecol. 42:1212-1225.

Paudel, J., Copley, T., Amirizian, A., Prado, A., and Bede, J. C. 2013 Arabidopsis redox status in response to caterpillar herbivory. Front. Plant Sci. 4:113.

Paudel, J. R., Amirizian, A., Krosse, S., Giddings, J., Ismail, S. A. A., Xia J. G., Gloer, J. B., van Dam, N. M., and Bede, J. C. 2016. Effect of atmospheric carbon dioxide levels and nitrate fertilization on glucosinolate biosynthesis in mechanically damaged Arabidopsis plants. BMC Plant Biol. 16:68

Paudel, J. R., and Bede, J. C. 2015. Ethylene signaling modulates herbivoreinduced defense responses in the model legume Medicago truncatula. Mol Plant-Microbe Interact. 28:569-579.

Pauwels, L., Barbero, G. F., Geerinck, J., Tilleman, S., Grunewald, W., Pérez, A. C., Chico, J. M., Vanden Bossche, R., Sewell, J., Gil, E., GarcíaCasado, G., Witters, E., Inzé, D., Long, J. A., De Jaeger, G., Solano, R. and Goosens, A. 2010. NINJA connects the co-repressor TOPLESS to jasmonate signaling. Nature 464:788-791.

Peiffer, M., and Felton, G. W. 2009. Do caterpillars secrete "oral secretions"? J. Chem. Ecol. 35:326-335.

Penninckx, I. A. M. A., Eggermont, K., Terras, F. R. G., Thomma, B. P. H. J., De Samblanx, G. W., Buchala, A., Métraux, J. P., Manners, J. M., and Broekaert, W. F. 1996. Pathogen-induced systemic activation of a plant defensin gene in Arabidopsis follows a salicylic acid-independent pathway. Plant Cell 8:2309-2323.

Penninckx, I. A. M. A., Thomma, B. P. H. J., Buchala, A., Métraux, J.-P., and Broekaert, W. F. 1998. Concomitant activation of jasmonate and ethylene response pathways is required for induction of a plant defensin gene in Arabidopsis. Plant Cell 10:2103-2113.

Pieterse, C. M. J., van der Does, D., Zamioudis, C., Leon-Reyes, A., and van Wees, S. C. M. 2012. Hormonal modulation of plant immunity. Annu. Rev. Cell Dev. Biol. 28:489-521.

Pogue, M. G. 2003. World Spodoptera database (Lepidoptera: Noctuidae) U.S. Department of Agriculture, Systematics and Entomology Laboratory, Beltsville, MD.

Potter, S., Uknes, S., Lawton, K., Winter, A. M., Chandler, D., DiMaio, J., Novitzky, R., Ward, E., and Ryals, J. 1993. Regulation of a hevein-like gene in Arabidopsis. Mol. Plant-Microbe Interact. 6:680-685.

Pré, M., Atallah, M., Champion, A., de Vos, M., Pieterse, C. M. J., and Memelink, J. 2008. The AP2/ERF domain transcription factor ORA59 integrates jasmonic acid and ethylene signals in plant defense. Plant Physiol. 147:1347-1357.

Proietti, S., Caarls, L., Coolen, S., Van Pelt, J. A., Van Wees, S. C. M., and Pieterse, C. M. J. 2018. Genome-wide association study reveals novel players in defense hormone crosstalk in Arabidopsis. Plant Cell Environ. 41:2342-2356. 
Ramírez, V., Van der Ent, S., Garcia-Andrade, J., Coego, A., Pieterse, C. M. J., and Vera, P. 2010. OCP3 is an important modulator of NPR1mediated jasmonic acid-dependent induced defenses in Arabidpsis. BMC Plant Biol. 10:199.

Ratzka, A., Vogel, H., Kliebenstein, D. J., Mitchell-Olds, T., and Kroymann, J. 2002. Disarming the mustard oil bomb. Proc. Natl. Acad. Sci. U.S.A. 99: 11223-11228

Rehrig, E. M., Appel, H. M., Jones, A. D., and Schultz, J. C. 2014. Roles for jasmonate- and ethylene-induced transcription factors in the ability of Arabidopsis to respond differentially to damage caused by two insect herbivores. Front. Plant Sci. 5:407.

Reymond, P., Weber, H., Damond, M., and Farmer, E. E. 2000. Differential gene expression in response to mechanical wounding and insect feeding in Arabidopsis. Plant Cell 12:707-719.

Rivera-Vega, J., Stanley, B. A., Stanley, A., and Felton, G. W. 2018. Proteomic analysis of labial saliva of the generalist cabbage looper (Trichoplusia ni) and its role in interactions with host plants. J. Insect Physiol. 107:97-103.

Robert-Seilaniantz, A., Grant, M., and Jones, J. D. J. 2011. Hormone crosstalk in plant disease and defense: More than just JASMONATESALICYLATE antagonism. Annu. Review Phytopathol. 49:317-343.

Robinson, G. S., Ackery, P. R., Kitching, I. J., Beccaloni, G. W., and Hernández, L. M. 2010. HOSTS - A database of the world's lepidopteran hostplants. Natural History Museum, London. https://www.nhm.ac.uk/.

Rossel, J. B., Wilson, P. B., Hussain, D., Woo, N. S., Gordon, M. J., Mewett, O. P, Howell, K. A., Whelan, J., Kazan, K., and Pogson, B. J. 2007. Systematic and intracellular responses to photooxidative stress in Arabidopsis. Plant Cell 19:4091-4110.

Sakamoto, H., Maruyama, K., Sakuma, Y., Meshi, T., Iwabuchi, M., Shinozaki, K., and Yamaguchi-Shinozaki, K. 2004. Arabidopsis Cys2/His2type zinc-finger proteins function as transcription repressors under drought, cold, and high salinity stress conditions. Plant Physiol. 136: 2734-2746.

Schlaeppi, K., Bodenhausen, N., Buchala, A., Mauch, F., and Reymond, P. 2008. The glutathione-deficient mutant pad2-1 accumulates lower amounts of glucosinolates and is more susceptible to the insect herbivore Spodoptera littoralis. Plant J. 55:774-786.

Schmelz, E. A., Carroll, M. J., LeClere, S., Phipps, S. M., Meredith, J., Chourey, P. S., Alborn, H. T., and Teal, P. E. A. 2006. Fragments of ATP synthase mediated plant perception of insect attack. Proc. Natl. Acad. Sci. U.S.A. 103:8894-8899.

Schmelz, E. A., Huffaker, A., Carroll, M. J., Alborn, H. T., Ali, J. G., and Teal, P. E. A. 2012. An amino acid substitution inhibits specialist herbivore production of an antagonist effector and recovers insect-induced plant defenses. Plant Physiol. 160:1468-1478.

Scholz, S., Reichelt, M., Boland, W., and Mithöfer, A. 2015. Additional evidence against jasmonate-induced jasmonate induction hypothesis. Plant Sci. 239:9-14

Schramm, K., Vassão, D. G., Reichelt, M., Gershenzon, J., and Wittstock, U. 2012. Metabolism of glucosinolate-derived isothiocyanates to glutathione conjugates in generalist lepidopteran herbivores. Insect Biochem. Mol. Biol. 42:174-182.

Schroff, R., Vergara, F., Muck, A., Svatoš, A., and Gershenzon, J. 2008. Nonuniform distribution of glucosinolates in Arabidopsis thaliana leaves has important consequences for plant defense. Proc. Natl. Acad. Sci. U.S.A. 105:6196-6201.

Schuman, M., and Baldwin, I. T. 2016. The layers of plant responses to insect herbivores. Annu Rev Entomol 61:373-394.

Schweizer, F., Fernández-Calvo, P., Zander, M., Diez-Diaz, M., Fonseca, S., Glauser, G., Lewsey, M. G., Ecker, J. R., Solano, R., and Reymond, P. 2013. Arabidopsis basic helix-loop-helix transcription factors MYC2, MYC3 and MYC4 regulate glucosinolate biosynthesis, insect performance, and feeding behaviour. Plant Cell 25:3117-3132.

Sewelam, N., Jaspert, N., Van Der Kelen, K., Tognetti, V., Schmitz, J., Frerigmann, H., Stahl, E., Zeier, J., Van Breusegem, F., and Maurino, V. G. 2014. Spatial $\mathrm{H}_{2} \mathrm{O}_{2}$ signaling specificity: $\mathrm{H}_{2} \mathrm{O}_{2}$ from chloroplasts and peroxisomes modulates the plant transcriptome differentially. Mol. Plant 7: 1191-1210.

Sheard, L. B., Tan, X., Mao, H. B., Withers, J., Ben-Nissan, G., Hinds, T. R., Kobayashi, Y., Hsu, F.-F., Sharon, M., Browse, J., He, S. Y., Rizo, J., Howe, G. A., and Zheng, N. 2010. Jasmonate perception by inositolphosphate-potentiated COI1-JAZ co-receptor. Nature 468:400-405.

Shearer, H. L., Cheng, Y. T., Wang, L., Liu, J., Boyle, P., Després, C., Zhang, Y., Li, X., and Fobert, P. R. 2012. Arabidopsis clade I TGA transcription factors regulates plant defenses in an NPR1-independent fashion. Mol. Plant-Microbe Interact. 25:1459-1468.

Shigenaga, A. M., and Argueso, C. T. 2016. No hormone to rule them all: Interactions of plant hormones during the responses of plants to pathogens. Seminars Cell Develop. Biol. 56:174-189.
Shroff, R., Vergara, F., Muck, A., Svatoš, A., and Gershenzon, J. 2008. Nonuniform distribution of glucosinolates in Arabidopsis thaliana leaves has important consequences for plant defense. Proc. Natl. Acad. Sci. U.S.A. 105:6196-6201.

Spoel, S. H., Koornneef, A., Claessens, S. M. C., Korzellus, J. P., Van Pelt, J. A., Mueller, J. A., Buchala, A. J., Métraux, J., Brown, R., Kazan, K., Van Loon, L. C., Dong, X., and Pieterse, C. M. J. 2003. NPR1 modulates crosstalk between salicylate- and jasmonate-dependent defense pathways through a novel function in the cytoplasm. Plant Cell 15:760-770.

Stefansky, W. 1971. Rejecting outliers by maximum normed residual. Ann. Math. Stat. 42:35-45.

Stotz, H. U., Pittendrigh, B. R., Kroymann, J., Weniger, K., Fritsche, J., Bauke, A., and Mitchell-Olds, T. 2000. Induced plant defense responses against chewing insects: Ethylene signaling reduces resistance of Arabidopsis against Egyptian cotton worm but not diamondback moth. Plant Physiol. 124:1007-1017.

Sun, Y., Fan, X.-Y., Cao, D.-M., He, K., Tang, W., Zhu, J.-Y., He, J.-X., Bai, M.-Y., Zhu, S., Oh, E., Patil, S., Kim, T.-W., Ji, H., Wong, W. H., Rhee, S. Y., and Wang, Z.-Y. 2010. Integration of brassinosteroid signal transduction with the transcriptional network for plant growth regulation in Arabidopsis. Dev. Cell 19:765-777.

Tada, Y., Spoel, S. H., Pajerowska-Mukhtar, K., Mou, Z., Song, J., Wang, C., Zuo, J., and Dong, X. 2008. Plant immunity requires conformational changes of NPR1 via $S$-nitrosylation and thioredoxins. Science 321: 952-956.

Taki, N., Sasaki-Sekimoto, Y., Obayashi, T., Kikuta, A., Kobayashi, K., Ainai, T., Yagi, K., Sakurai, N., Suzuki, H., Masuda, T., Takamiya, K., Shibata, D., Kobayashi, Y, and Ohta, H. 2005. 12-Oxo-phytodienoic acid triggers expression of a distinct set of genes and plays a role in wound-induced gene expression in Arabidopsis. Plant Physiol. 139: 1268-1283.

Thines, B., Katsir, L., Melotto, M., Niu, Y., Mandaokar, A., Liu, G., Nomura K., He, Y. S., Howe, G. A., and Browse, J. 2007. JAZ repressor proteins are targets of the $\mathrm{SCF}^{\mathrm{COI} 1}$ complex during jasmonate signalling. Nature 448:661-665.

Thivierge, K., Prado, A., Driscoll, B. T., Bonneil, É., Thibault, P., and Bede, J. C. 2010. Caterpillar- and salivary-specific modification of plant proteins. J. Proteome Res. 9:5887-5895.

Tian, D., Peiffer, M., Shoemaker, E., Tooker, J., Haubruge, E., Francis, F., Lutheran, D. S., and Felton, G. W. 2012. Salivary glucose oxidase from caterpillars mediates the induction of rapid and delayed-induced defenses in the tomato plant. PLoS One 7:e36168.

Touw, A. J., Verdecia Mogena, A., Maedicke, A., Sontowski, R., van Dam, N. M., and Tsunoda, T. 2020. Both biosynthesis and transport are involved in glucosinolate accumulation during root-herbivory in Brassica rapa. Front. Plant Sci. 10:1653

Van der Does, D., Leon-Reyes, A., Koornneef, A., Van Verk, M. C., Rodenburg, N., Pauwels, L., Goossens, A., Körbes, A. P., Memelink, J., Ritsema, T., Van Wees, S. C. M., and Pieterse, C. M. J. 2013. Salicylic acid suppresses jasmonic acid signaling downstream of SCF ${ }^{\mathrm{COI1}}$-JAZ by targeting GCC promoter motifs via transcription factor ORA59. Plant Cell 25: $744-761$

Vanderauwera, S., Zimmermann, P., Rombauts, S., Vandenabeele, S., Langebartels, C., Gruissem, W., Inze D., and Van Breusegem, F. 2005. Genome-wide analysis of hydrogen peroxide-regulated gene expression in Arabidopsis reveals a high light-induced transcriptional cluster involved in anthocyanin biosynthesis. Plant Physiol. 139:806-821.

Verhage, A., Vlaardingerbroek, I., Raaymakers, C., Van Dam, N. M., Dicke, M., Van Wees, S. C. M., and Pieterse, C. M. J. 2011. Rewiring of the jasmonate signaling pathway in Arabidopsis during insect herbivory. Front. Plant Sci. 2:47.

Vogel, H., Kroymann, J., and Mitchell-Olds, T. 2007. Different transcript patterns in response to specialist and generalist herbivores in the wild Arabidopsis relative Boechera divaricarpa. PLoS One 2:e1081.

Vos, I. A., Verhage, A., Schuurink, R. C., Watt, L. G., Pieterse, C. M. J., and Van Wees, S. C. M. 2013. Onset of herbivore-induced resistance in systemic tissue primed for jasmonate-dependent defenses is activated by abscisic acid. Front. Plant Sci. 4:539.

Wang, Z., Cao, G., Wang, X., Miao, J., Liu, X., Chen, Z., Qu, L.-J., and Gu, H. 2008. Identification and characterization of COI1-dependent transcription factor genes involved in JA-mediated response to wounding in Arabidopsis plants. Plant Cell Rep. 27:125-135.

Wasternack, C., and Hause, B. 2013. Jasmonates: Biosynthesis, perception, signal transduction and action in plant stress response, growth and development. An update to the 2007 review in Annals of Botany. Ann. Bot. 111:1021-1058

Wasternack, C., and Song, S. 2017. Jasmonates: Biosynthesis, metabolism and signaling by proteins activating and repressing transcription. J. Exp. Bot. 68:1303-1321. 
Weech, M. H., Chapleau, M., Pan, L., Ide, C., and Bede, J. C. 2008. Caterpillar saliva interferes with induced Arabidopsis thaliana defence responses via the systemic acquired resistance pathway. J. Exp. Bot. 59: 2437-2448.

Wittstock, U., and Burow, M. 2010. Glucosinolate breakdown in Arabidopsis: Mechanism, regulation and biological significance. The Arabidopsis Book 8:e0134.

Wittstock, U., and Gershenzon, J. 2002. Constitutive plant toxins and their role in defense against herbivores and pathogens. Curr. Opin. Plant Biol. 5: 300-307.

Yan, J., Zhang, C., Gu, M., Bai, Z., Zhang, W., Qi, T., Cheng, Z., Peng, W., Luo, H., Nan, F., Wang, Z., and Xie, D. 2009. The Arabidopsis CORONOTINE INSENSITIVE1 protein is a jasmonate receptor. Plant Cell 21:2220-2236.

Yoshinaga, N., Alborn, H. T., Nakanishi, T., Suckling, D. M., Nishida, R., Tumlinson, J. H., and Mori, N. 2010. Fatty acid-amino acid conjugates diversification in lepidopteran caterpillars. J. Chem. Ecol. 36:319-325.

Zander, M., Chen, S., Imkampe, J., Thurow, C., and Gatz, C. 2012. Repression of the Arabidopsis thaliana jasmonic acid/ethylene-induced defense pathway by TGA-interacting glutaredoxins depends on their C-terminal ALWL motif. Mol. Plant 5:831-840.
Zander, M., La Camera, S., Lamotte, O., Métraux, J.-P., and Gatz, C. 2010. Arabidopsis thaliana class-II TGA transcription factors are essential activators of jasmonic acid/ethylene-induced defense responses. Plant J. 61: 200-210.

Zander, M., Lewsey, M. G., Clark, N. M., Clark, N. M., Yin, L., Barlett, A., Saldierna Guzman, J. P., Hann, E., Langford, A. E., Jow, B., Wise, A, Nery, J. R., Chen, H., Bar-Joseph, Z., Walley, J. W., Solano, R., and Ecker, J. R. 2020. Integrated multi-omics framework of the plant response to jasmonic acid. Nat. Plants 6:290-302.

Zander, M., Thurow, C., and Gatz, C. 2014. TGA transcription factors activate the salicylic acid-suppressible branch of the ethylene-induced defense program by regulating ORA59 expression. Plant Physiol. 165: 1671-1683.

Zarei, A., Körbes, A. P., Younessi, P., Montiel, G., Champion, A., and Memelink, J. 2011. Two GCC boxes and AP2/ERF-domain transcription factor ORA59 in jasmonate/ethylene-mediated activation of the PDF1.2 promoter in Arabidopsis. Plant Mol. Biol. 75:321-331.

Zhai, Q., Yan, L., Tan, D., Chen, R., Sun, J., Gao, L., Dong, M.-Q., Wang, Y., and $\mathrm{Li}, \mathrm{C}$. 2013. Phosphorylation-coupled proteolysis of the transcription factor MYC2 is important for jasmonate-signaled plant immunity. PLoS Genetics 9:e1003422. 